\title{
Late Pleistocene and Earliest Holocene avifauna from the Loutra Almopias Cave (Macedonia, Greece)
}

\author{
Zlatozar Boev ${ }^{1}$, Evangelia Tsoukala ${ }^{2}$
}

\begin{abstract}
1 National Museum of Natural History, Bulgarian Academy of Sciences, 1 Tsar Osvoboditel Blvd., 1000 Sofia, Bulgaria,boev@nmnhs.com; zlatozarboev@gmail.com (corresponding author)

2 Aristotle University, Geology School, GR-54124 Thessaloniki, Greece, lilits@geo.auth.gr
\end{abstract}

\begin{abstract}
The bird fauna of the Loutra Almopias Cave comprised eight orders, 22 families, 41 genera and at least 47 species (68 different taxa) established based on 551 avian bone finds. The Loutra Almopias Cave is a new (26 $\left.{ }^{\text {th }}\right)$ Pleistocene avian locality in Greece. About $92.5 \%$ of the material was dated to the Earliest Holocene $(11.230 \pm 110$ y. BP), coming from the upper chamber of the cave, whereas an older assemblage was dated to the Late Pleistocene (37,880 y. $\pm 370 / 360 \mathrm{BP})$, coming from the floor chambers of the cave. Here is provided the first fossil record of 13 species in Greece (Buteo lagopus, Francolinus francolinus, Lagopus lagopus, Bonasa bonasia, Dryocopus martius, Lulula arborea, Bombicylla garrulus, Cinclus cinclus, Sylvia borin, Carduelis carduelis, Loxia curvirostra, Plectrophenax nivalis and Emberiza cirlus). Three genera (Francolinus, Anthus and Riparia/Ptyonoprogne) were established for the first time in Pleistocene deposits in the country. The record of Fr. francolinus was the first one for the Balkans and Eastern Europe. At both sites inside the cave, regardless of their different age, the habitat preferences of the identified bird species indicated that the surrounding paleoenvironment included both grassy openlands (dominated by gramineans) and woodland (coniferous or mixed woods). In addition, rocky habitats were represented in the surroundings of the locality. The presence of small species of Perdicinae (26\%) and corvids (34\%) indicated the former existence and prevelance of open grassy fields and rocky environments. The Alpine chough was the most abundant species at both localities. In the Earliest Holocene it comprised 29.5\%, whereas in the Late Pleistocene it reached $25.6 \%$ of the material. Such a representation suggests a natural non-human accumulation of the material, probably due to the feeding behavior of Bubo bubo. The Late Pleistocene record (19 taxa; 41 finds) included Falco sp. cf. F. peregrinus, Perdix perdix, Perdix sp., Alectoris graeca, Alectoris sp., Lagopus cf. lagopus, cf. Bonasa bonasia, Columba livia, Columba palumbus, Bubo bubo, Melanocorhypha calandra, Anthus sp., Turdus sp., Pica pica, Pyrrhocorax graculus, Loxia curvirostra, Coccothraustes coccothraustes, Pyrrhula pyrrhula, Fringillidae gen. indet., non-Passeriformes indet. and also suggests the site has been used by the eagle owl. The climate probably used to be drier and cooler than in the Earliest Holocene. The record of 17 woodland species from the Earliest Holocene that were absent in the Late Pleistocene could be explained by the more humid and moderate climate at the very end of the Pleistocene.
\end{abstract}

Key words: Quaternary avifauna, Balkans, fossil birds, paleoenvironment, Francolinus.

\section{Introduction}

The bear cave site (Loutra Almopias Cave: LAC) is located in northern Greece, NW of and about $120 \mathrm{~km}$ from Thessaloniki (Fig. 1). The investigations of the area have lasted more than 20 years and the site has yielded abundant cave bear remains among large mammals, as well as micromammals. All these consist 
the older fauna of 37,880 y. $\pm 370 / 360$ BP from the sediments of the cave floor, from chambers on the ground floor LAC I, LAC II, LAC III, LAC Ib and LAC Ic (Rabeder et al. 2006), whereas younger fauna of $11,230 \pm 110 \mathrm{y}$. BP (Rabeder pers. comm.) was excavated from the upper chamber LAC Ia. It is reffered to the Earliest Holocene, as the base of Holocene is 11,700 y., (Walker et al, 2009).Thus, actually two localities in the cave have been explored: (1) of Late Pleistocene age and (2) of Earliest Holocene age. From both sites a total of $>50,000$ faunal remains were collected mainly using the sieving procedure (Tsoukala et al., 2006; Rabeder et al., 2006). Among them, avian remains represented ca. $1.1 \%$, but they included the most diverse taxonomic group of the uncovered fauna (47 species at least; see bellow).

Data on the Pleistocene birds of Greece are scanty. A total of 26 localities are known, mostly from Crete and Central Greece, (Tyrberg, 1998, 2008; Mlíkovský, 1995, 2007; Bochenski \& Tomek, 2010; Wilczyński et al., 2016; Bochenski et al., 2018). Only two localities are known from Northern Greece: Elaiochoria 3 (Mlíkovský, 1995) and Petralona (Mlíkovský, 2007). Geochronologically the localities have been divided into: Early Pleistocene (5); Middle Pleistocene (3); Late Pleistocene (14) and undated (2). So far, the material from the Liko Cave (Crete) provided the most diverse Pleistocene avifauna in Greece (Tyrberg, 1998; 2008).

\section{Material and methods}

The material (a total of 551 avian bones and bone fragments and splinters; Plates 1-5) was collected from two sites in the cave: one (LAC I, II, III, Ib and Ic) dated to the Late Pleistocene (LP) and the other (LAC Ia) dated to the Earliest Holocene (Tsoukala et al., 2006, Rabeder et al., 2006). The great majority of the material (92.5\%) originated from deposits of the upper chamber LAC Ia and was dated to the EEH. It was collected through screening and washing of the sediments of the cave. The washing procedure was carried out using two double sieve systems: the upper sieve (a mesh of 3-5 mm) for the largest remains and milk teeth and the lower sieve (a mesh $0.8 \mathrm{~mm}$ ) mainly for micromammals, avian, reptilian and other smaller faunal remains. The material was handed for examination at the NMNHS in July 2009. It is housed in the LGPUT (LAC B1 - 551). All material per taxa is listed in Appendix 1.

The finds were identified through comparison with corresponding skeletal elements of recent bird species from the collection of the Vertebrates Department of NMNHS. All measurements were taken using calipers to $0.01 \mathrm{~mm}$ accuracy. All generic names of the binominals are given abbreviated in the text and are in full in Table 1. Further explanations of the measurements are shown in Fig. 2. All finds belong to adults (ad.), unless other individual age is indicated. The taxonomy follows del Hoyo \& Collar (2014, 2016). The osteological terminology is after Baumel \& Witmer (1993) and, in some respects, after Livezey \& Zusi (2006).

\section{Abbreviations}

\section{Anatomical}

cmc: carpometacarpus; dex.: dextra; d.: digitus, digiti; dist.: distalis, distal; f. a.: facies articularis; hum.: humerus; max.: maximal; min.: minimal; mt.: metatarsi (tarsometatarsal); ph.: phalanx, phalangeal; p.: pedis; proc.: processus, processi; prox.: proximalis; sin.: sinistra; s. a.: sulcus articularis; tbt: tibiotarsus; tmt: tarsometatarsus; tr.: trochlea.

\section{Institutional}

NMNHS: National Museum of Natural History (Bulgarian Academy of Sciences), Sofia, Bulgaria; SMF: Senckenberg Forschungsinstitut und Naturmuseum, Frankfurt am Main, Germany; LGPUT: Laboratory of Geology and Paleontology, Aristotle University of Thessaloniki, Greece.

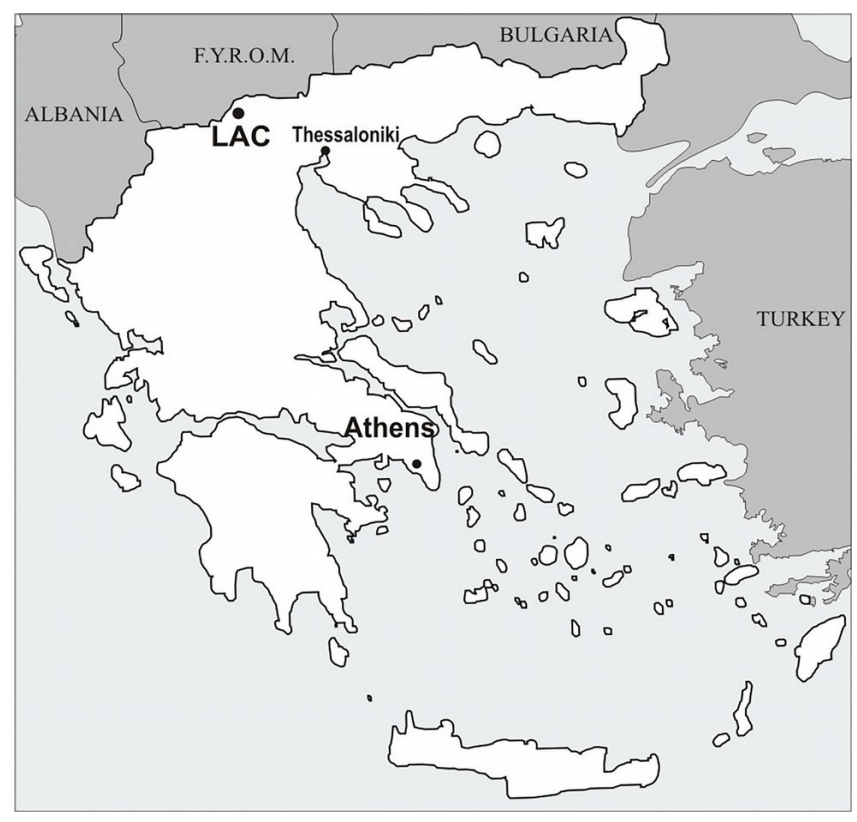

Fig. 1. Map of Greece with the location of the cave site LAC in Almopia Speleopark (Macedonia, Northern Greece). (LAC: Loutra Almopias Cave). 


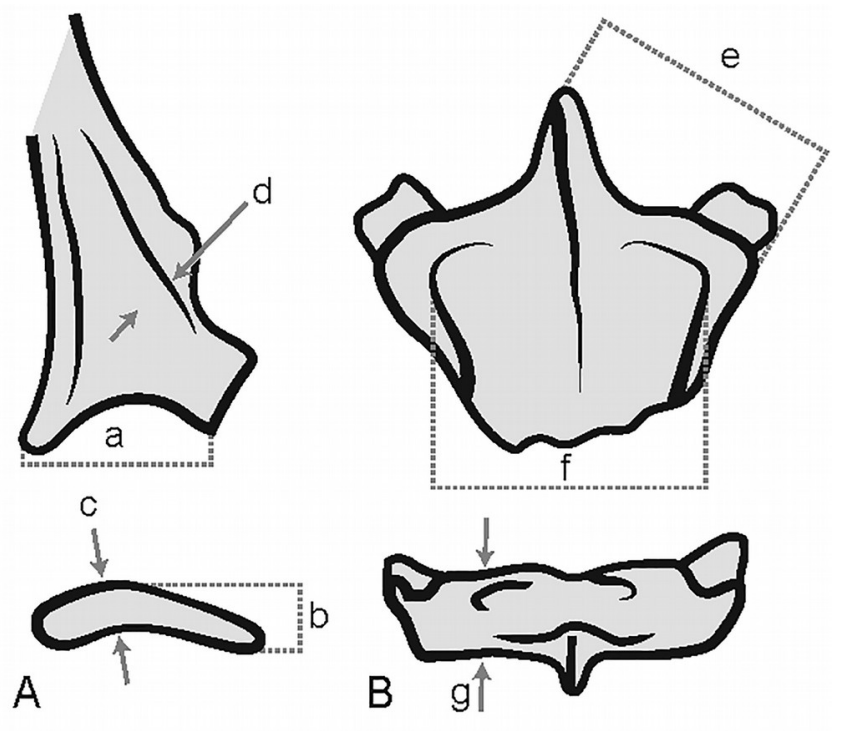

Fig. 2. Scheme for measuring the bones: A - os coracoideum, pars sternalis: a - length of crista articularis sternalis; b - height at crista articularis sternalis; c thickness at crista articularis sternalis; $d$ - thickness at the base of proc. lateralis; B - sternum, pars coracoidalis: e length of sulcus articularis coracoideus; f - basal width; g min. thickness of corpus sterni.

\section{Other}

ad.: adult; EP: Early Pleistocene; f.: former; juv.: juvenile; LAC: Loutra Almopias Cave; LAC B: Loutra Almopias Cave Bird Collection; LP: Late Pleistocene; EEH: Earliest Holocene; MNI: minimum number of individuals; MP: Middle Pleistocene; EP: Early Pleistocene; sad.: subadult; UK: United Kingdom; \#: the specimen differs (significantly); > and $<$ : the specimen is considerably bigger/ smaller.

\section{Results}

\section{Taxa represented in the Loutra Almopias Cave}

The revealed avian fauna was rather diverse and included eight orders, 22 families, 41 genera and at least 47 species (68 taxa), established based on 551 bone finds, i. e. each of the established species/taxon was represented by an average of 8.1 finds. See Appendix 1 for detailed list of specimens.

Galliformes Temminck, 1824

Phasianidae Vigors, 1825

Perdix perdix (Linnaeus, 1758). (P1. 1, Fig. 4) Known from the EP to LP from numerous Eurasian localities from France to Syria and China (Tyrberg, 1998; 2008). The locality falls within the recent breeding range of the species (Hagemeijer \& Blair, 1997).
Occurs mainly in moister grasslands, grass moors, heathlands, borders of bog and marshland, steppes, alpine and lowland meadows and open scrubs (Harrison, 1982).

Perdix sp. Finds of Perdix sp. are known from the MP to LP from numerous localities in China, $f$. Czechoslovakia, France, Israel and Portugal (Tyrberg, 1998; 2008). Perdix cf. jurcsaki has been established in the Early Middle and MP of Petralona (Chalkidiki), while Perdix palaeoperdix - from the EP of Tourkobounia 2 (Attiki) (Tyrberg, 1998). The material from LAC did not allow identification to species level. Alectoris graeca (Meisner, 1804). (Pl. 1, Fig. 5) Known from numerous MP to LP Eurasian localities from France to Uzbekistan (Tyrberg, 1998). Recently found in the LP in Mališina Stijena (Montenegro; Bogoćević \& Dimitriević, 2004). In Greece, the species is known from the LP of the Elaiochoria 3 (Chalkidiki), Kephalari (Argolis), Kitsos (Attiki), the EP of Petralona (Chalkidiki; A. g. mediterranea Mourer-Chauviré, 1975) (Tyrberg, 1998; 2008) and from the LP of the Klissoura Cave 1 (Bochenski \& Tomek, 2010). The locality falls within the recent species range (Hagemeijer \& Blair, 1997). Occurs mainly in dry bare rocky hillsides with scattered trees and sparse shrubby vegetation, thicker scrubs and open woodlands (Harrison, 1982). The listed skeletal elements are typical for phasianids and for Alectoris (of the graeca/chukar group). As Bochenski (2007) states, they are hardly distinguishable osteologically. Regarding their dimensions, they all corresponded to this group (Kraft, 1972). The comparisons of the fossil fragments with the bones of recent specimens indicated considerable similarity to A. graeca.

Alectoris sp. Known from the EP to LP from France, f. Czechoslovakia, Italy and Spain (Tyrberg, 1998; 2008). In Greece, Alectoris sp. is known from the MP of Petralona (Chalkidiki), the LP of Vraóna (Attiki) (Tyrberg, 1998). Finds of cf. Alectoris sp. are also known from the LP of the Klissoura Cave I (Argolis) (Tyrberg, 2008).

Francolinus francolinus (Linnaeus, 1766). (Pl. 1, Figs. 6-10) Both finds were compared with those of nine species of Perdicinae and Tetraonidae (Tables 2, $3)$.

B 150: The morphology fully agreed with the coracoid of $F$. francolinus and clearly distinguished it from all other listed genera/species. Dimensionally it also was closer to the black francolin. It could be distinguished clearly from L. muta and B. bonasia based on the much shorter processus lateralis coracoidei and the much deeper bow of crista articularis sternalis. B 163: In cranial view the find clearly differed from L. muta because of the considerably thicker labrum internum coracoidei. In 
dorsal view it had two well-developed fossa separated by a protruding ridge, completely absent in L. muta and $B$. bonasia. Previous fossil records of $F$. francolinus originate only from the LP of Spain, Israel, Syria, Iraq and Iran (Tyrberg, 1998). So far, Fr. francolinus has not been established from Greece and the Balkans nor from Eastern Europe at all (Tyrberg, 1998; 2008). Francolinus capeki Lambrecht, 1933 is known from the MP of Croatia, Francolinus sp. - from the EP of Croatia. Until the $19^{\text {th }}$ century, $F r$. francolinus was spread in the $\mathrm{W}$ Mediterranean, but the present range approaches westwards up to $\mathrm{S}$ Turkey and Cyprus (Babayev et al., 1997). The locality lies outside of the recent breeding range of the species (Hagemeijer \& Blair 1997). Occurs mainly in moister areas with good growth of vegetation, shrubby thickets bordering watercourses and lakes, extensive areas of scrub or shrubby herbage, lush grasses, marshy areas with tall herbage and grasses, forest edges, forest clearings within the $26^{\circ} \mathrm{C}$ July isotherm (Harrison, 1982). Its historical range includes SE Spain and Sicily and probably some Aegean Islands (until the middle of $19^{\text {th }}$ century; Harrison, 1982). In general, all the francolins' records in the Pleistocene deposits are scant. According to Tyrberg (1998), five species of Francolinus Stephens, 1819 have been recorded in the Palearctic, four of them in Europe. Mourer-Chauviré (1993) considers Francolinus spp. as Tertiary relicts, which have progressively vanished in the Pleistocene.

Francolinus sp. The finds clearly differed dimensionally from Perdix and Alectoris (and Lagopus and Bonasa) (Table 2). Some measurements differed by ca. $30 \%$ of the measurement value (for example measurement "d" of A. graeca, "b" of $P$. perdix, "c" of L. lagopus, etc.).

Alectoris/Francolinus. Both phalangeal finds were thinner than A. graeca. Based on their size and overall morphology, they could be attributed to a phasianid species, close to Alectoris or Francolinus, but precise identification was not possible.

Perdix/Francolinus. The five phalangeal finds were smaller, shorter and thicker than P. perdix. Based on their size and overall morphology, they could be attributed to a phasianid species, close to Perdix or Francolinus, but precise identification was not possible.

Perdicinae gen. indet. This material (seven pedal phalanges) needs further detailed comparisons of wider series of specimens (mainly francolins, Ammoperdix spp.), but it could be attributed to Perdicinae, based on the size and morphological similarity (round profile of the distal end and compact phalangeal body of the ph. 1 and 2).
Tetraonidae Vigors, 1825

Tetrao tetrix Linnaeus, 1758. (Pl. 1, Fig. 11) The find (left ulnare bone) completely fitted the size and shape of the compared black grouses. Known from the EP to LP from Spain to Ukraine (Tyrberg, 1998; 2008). In Greece, the species is known from the LP of Elaiochoria 3 (Chalkidiki) (Tyrberg, 1998). The locality lies outside of the recent breeding range of the species. Until 1990, the species still has been breeding in the north-westernmost parts of the neighboring North Macedonia (Hagemeijer \& Blair 1997). It occurs mainly in conifer and birch forests along forest edges, in open forests and areas of rock and broken woodland scrubs, swampy heathlands, moorlands and bogs within the $11^{\circ} \mathrm{C}$ and $21-24^{\circ} \mathrm{C}$ July isotherms (Harrison, 1982).

Lagopus cf. lagopus (Linnaeus, 1758). (P1. 1, Fig. 12; P1. 2, Figs. 1-2) The find (distal/claw/pedal phalanx and a symphysal half of a furcula) fitted the size and shape of the compared willow ptarmigan. Known from the EP to LP from numerous Eurasian localities from Spain to Ukraine (Tyrberg, 1998; 2008). Recently, also found in the LP in Mališina Stijena (Montenegro; Bogoćević \& Dimitriević, 2004). Until now, the species has not been established in fossil records from Greece. The locality lies outside of the recent breeding range of the species (Hagemeijer \& Blair, 1997). Occurs mainly in swampy scrub tundra, marshy heathlands, bogs in conifer forests, birch and willow forests, riverine scrubs of steppes (Harrison, 1982).

aff. Lagopus sp. With typical shape and proportions of a gallinaceous bird. Dimensionally close to the genus Alectoris, but the general proportions were similar to Tetraonidae, especially its size, which indicated that it should be considered as a member of Lagopus. Two species of Lagopus used to be widely distributed in the Pleistocene of Europe, established in numerous localities far south of the recent breeding range. All of them were dated to the Late Pleistocene (Tyrberg, 1998; 2008).

cf. Bonasa bonasia (Linnaeus, 1758). (Pl. 2, Figs. 3-4) Thick and compact trochlea metatarsi IV; dimensions resembled much to that of the hazel grouse. Known from the MP to LP of numerous localities from Spain to Russia (Tyrberg, 1998). So far, the species has not been established in the fossil record of Greece (Tyrberg, 1998; 2008). The locality falls within the recent breeding range of the species (Hagemeijer \& Blair, 1997). Occurs mainly in thick forests with undergrowth, mountain conifer forests, spruce forests with bilberry layer, mixed forests with undershrubs, beech forests and riverine alder forests 
within the $13^{\circ} \mathrm{C}$ and $21-22^{\circ} \mathrm{C}$ July isotherm (Harrison, 1982).

Bonasa bonasia/Lagopus muta. The size and morphology of the three pedal phalanges suggested a small tetraonid. Further identification was not possible.

Columbiformes (Latham, 1790)

Columbidae (Illiger, 1811)

Columba livia Gmelin, 1789. (P1. 2, Fig. 7) Known from EP to LP from numerous Eurasian localities from Spain to Jordan and China (Tyrberg, 1998; 2008). In Greece, the species is known from the LP of Elaiochoria 3 (Chalkidiki) and Vraóna (Attiki) (Tyrberg, 1998); from the ?LP of the Liko Cave (Crete); the LP of the Kalamakia Cave (Lakonia) (Tyrberg, 2008) and from the LP of the Klissoura Cave 1 (Bochenski \& Tomek, 2010). The locality falls within the recent breeding range of the species (feral pigeon) (Hagemeijer \& Blair, 1997). Occurs mainly in rocky areas with nearby open spaces, rocky coasts and islands, rocky outcrops in mountains, in open grasslands or steppe (Harrison, 1982). Theoretically, a small part of the identified material could belong to Columba oenas Linnaeus, 1758, a species often undistinguishable osteomorphologically from the rock pigeon. On the other hand, the rock pigeon lives in flocks and usually is much more numerous. The only collected long bone (a distal fragment of a femur) did not allow firm determination, although Tomek \& Bochenski (2005) found that the two species differed in size to some extent.

Columba palumbus Linnaeus, 1758 (Pl. 2, Figs. 5-6). The distal pedal phalanx completely corresponded in terms of its bend and higher articular end to that of the wood pigeon. The bows of the symphysal portion of furcular also fitted that of $C$. palumbus. The wood pigeon is the only columbid species of Europe, which is much larger than the other pigeons and doves. Known from the EP to LP of numerous Eurasian localities from Spain to Georgia (Tyrberg, 1998; 2008). In Greece, the species is known from the MP of Petralona (Tyrberg, 1998) and the Liko Cave (Crete) (Tyrberg, 2008). The locality falls within the recent breeding range of the species (Hagemeijer \& Blair, 1997). It occurs mainly in broadleaf forests and forest edges (Harrison, 1982).

Caprimulgiformes Ridgway, 1881

Caprimulgidae Vigors, 1825
?Caprimulgus sp. (Pl. 2, Fig. 12). The find was tentatively referred to nightjars. Young individual with still distally infused metarsalia. General morphology suggested Caprimulgus. Known from the MP sites of France, Italy and from the LP of Croatia and Romania. Caprimulgus europaeus is known from the LP of the Liko Cave (Tyrberg, 1998; 2008). The locality lies within the recent breeding range of the species (Hagemeijer \& Blair, 1997). Occurs mainly in open or broken broadleaf, mixed or conifer forests, on forest edges and in clearings, in birch and poplar scrubland grass and scrub steppes and groves (Harrison, 1982).

Accipitriformes Vieillot, 1816

Accipitridae (Vieillot, 1816)

Buteo sp. cf. B. lagopus (Pontoppidan, 1763) (Pl. 1, Fig. 1). The size and morphology indicated a buzzard, while articular face and the profile of the phalangeal body much resembled those of $B$. lagopus (B. lagopus, $B$. buteo and $B$. rufinus have been compared). Known from the LP sites of Germany, f. Czechoslovakia, France, Hungary, Italy, Moldavia, Romania, Slovakia and Ukraine (Tyrberg, 1998; 2008). So far, the species has not been established in the fossil record of Greece. The locality lies outside of the recent breeding range of the species but falls within its present wintering range (Hagemeijer \& Blair, 1997), although on the Balkans it is a rare winter visitor (Cramp \& Simmons, 1980). It occurs mainly in open country, on bare moist tundra and shrub to forest tundra, bare upland moors and heathlands, mountains (Harrison, 1982).

Falconiformes (Sharpe, 1874)

Falconidae Vigors, 1824

Falco sp. cf. F. peregrinus Tunstall, 1771 (Pl. 1, Fig. 2 ). The three finds represented distal (claw) pedal phalanges of a large falcon. The comparison with all European large falcons showed greater similarity to the peregrine falcon. Known from the EP to LP of numerous Eurasian localities from France to Azerbaijan (Tyrberg, 1998). In Greece, the species is known from the ?LP of the Liko Cave (Crete) (Tyrberg, 1998; 2008). Recently found in the LP in Mališina Stijena (Montenegro; Bogoćević \& Dimitriević 2004). The locality falls within the recent breeding range of the species (Hagemeijer \& Blair, 1997). Occurs mainly in open habitats (from tundra and moorlands to steppes and scrubs) and rarely in forested areas. Widespread, but of very sporadic distribution (Harrison, 1982). 
Falco sp. ex gr. F. cherrug Gray, 1834. Large falcon. Further identification was impossible. Falco cherrug is known from EP to LP from Romania, $f$. Czechoslovakia, Croatia, Hungary, Slovenia, Ukraine and China (Tyrberg, 1998; 2008). So far, the species has not been established in the fossil record of Greece (Tyrberg, 1998). The locality lies outside of the recent breeding range of the species (Hagemeijer \& Blair, 1997) and probably it has survived in the neighboring regions in the country. Occurs mainly in open areas, areas with scattered trees, riverine areas, open forests and plaines, grass and tree steppes and mountain plateaus (Harrison, 1982). The find could be firmly determined only as "large falcon", i. e. Falco sp. ex gr. F. cherrug.

Falco sp. cf. tinnunculus (Linnaeus, 1758) (Pl. 1, Fig. 3). All finds were pedal phalanges of a small falcon of the "tinnunculus" group. The morphology and size excluded $F$. naumanni and $F$. vespertinus and inclined to the common kestrel. Known from numerous Eurasian localities of the EP to LP from Spain to Syria and China (Tyrberg, 1998; 2008). In Greece, the species is known from the LP of Kitsos (Atika), the Liko Cave (Crete), the Tylos, Vraóna (Attiki) (Tyrberg, 1998). The locality falls within the recent breeding range of the species (Hagemeijer \& Blair, 1997). Occurs mainly in open country, grassy or partly forested areas (Harrison, 1982).

Falco sp. cf. vespertinus Linnaeus, 1766. The four pedal phalanges of a small falcon resembled most to the ones of the red-footed falcon. Known from the EP of Hungary and Romania; the MP of $f$. Czechoslovakia, France and Hungary and from the LP of Bulgaria (cf.), Switzerland, Croatia, France, Georgia, Hungary, Italy, Moldavia, Romania, Spain and Ukraine (Tyrberg, 1998; 2008). Recently found in the LP of Mališina Stijena (Montenegro; Bogoćević \& Dimitriević, 2004). The locality lies outside of the recent breeding range of the species, but falls within its present wintering range (Hagemeijer \& Blair, 1997). Occurs mainly in drier open areas with scattered trees, woodlands, forest steppes, riverine forests and forest edges (Harrison, 1982).

Falco sp. ex gr. tinnunculus. The size and morphology of this pedal phalange firmly determines it only as a "small falcon", i. e. Falco sp. ex gr. tinnunculus.

\section{Strigiformes (Wagler, 1830)}

Strigidae (Vigors, 1825)

Bubo bubo (Linnaeus, 1758) (Pl. 2, Fig. 10). All finds (a tmt and seven pedal phalanges) of an owl fitted dimensionally only to the largest Eurasian owl, the eagle owl. Known from the EP to LP of numerous Eurasian localities from Spain to Jordan, Iraq, Syria and China (Tyrberg, 1998; 2008). So far, the species has been established in Greece in the Upper Palaeolithic deposits of the Klissoura Cave 1 (Bochenski \& Tomek, 2010). The Loutra Almopias Cave provides the second species record in Greece. The locality falls within the recent breeding range of the species (Hagemeijer \& Blair, 1997). Occurs mainly in rocky or wooded areas, from mountains and forests to low rocky outcrops in grasslands or semideserts, from dense forests to bare areas with groups of trees (Harrison, 1982).

Athene noctua (Scopoli, 1769). (P1. 2, Fig. 9) The only find (ph. 2 d. III p. dex. dist.) completely corresponded to that of the little owl. Known from EP to LP of numerous Eurasian localities from Spain to Israel, Syria and China (Tyrberg, 1998; 2008). In Greece, the species is known from the LP/MP of the SE Pigadia Cave (Karpathos), the LP of the Tylos and Vraóna (Attiki) (Tyrberg, 1998). The locality falls within the recent breeding range of the species (Hagemeijer \& Blair, 1997). Occurs mainly in more open country, open and broken forests and groves and areas with scattered trees or scrubs, rocky arid areas, steppes, semidesert and dry rocky mountains (Harrison, 1982).

cf. Otus scops (Linnaeus, 1758). (Pl. 2, Fig. 11) The sharp distal end of the phalanx and the sculpture of the articular surface, as well as its size, corresponded to the Eurasian scops owl. Known from the LP sites of Switzerland, Croatia, f. Czechoslovakia, Hungary, Italy, Moldavia, Portugal, Spain, Ukraine and Uzbekistan. In Greece, the species has been known from the LP of the Gumbes $\mathrm{C}$ and the Liko Cave (Crete) and the Tylos Island (Tyrberg, 1998; 2008). The locality lies within the recent breeding range of the species (Hagemeijer \& Blair, 1997). Occurs mainly in lightly forested regions, open or broken forests, riverine forests, areas with scattered trees (Harrison, 1982).

\section{Piciformes (Meyer et Wolf, 1810)}

Picidae Vigors, 1825 cf. Dryocopus martius (Linnaeus, 1758) (Pl. 3, Fig. 1). The large size and general shape (stumpy and strongly curved phal. body) suggested the find belonged to the black woodpecker. All other woodpeckers in the Western Palearctic have much smaller pedal ph. Known only from the LP of France, Georgia and Poland (Tyrberg, 1998; 2008). In Greece, the species has not been established in the fossil record (Tyrberg, 1998; 2008). The locality falls within the recent breeding range of the species (Hagemeijer \& Blair, 1997). Occurs 
mainly in climax forests, conifer forests with pines, mixed forests, climax beech forests, more open forests or partial clearings with dead timber and mountain forests (Harrison, 1982).

cf. Picidae. The second specimen of Piciformes from LAC Ia chamber was smaller than Dryocopus martius, but its morphology suggested that it could be referred to Picidae.

Passeriformes (Linnaeus, 1758)

Alaudidae (Vigors, 1825)

Galerida sp. cf. G. cristata Linnaeus, 1758 (Pl. 3, Fig. 3 ). The fragments of humerus and tarsometatarsi were characteristic of species of Alaudidae. The deep fossa pneumotricipitalis, the round caput humeri and the projected inception of crista pectoralis of an alaudid fitted to the ones of the crested lark. The shape of the almost parallel trochleae of the three distal portions of tmt also corresponded to the same species. The size, proportions and the shape of the osteological details pointed to G. cristata. Galerida cristata is known from the EP to LP from numerous Eurasian localities from Spain to Jordan and China (Tyrberg, 1998; 2008). The locality falls within the recent breeding range of the species (Hagemeijer \& Blair, 1997). It occurs mainly in lowlands, drier less vegetated areas, sandy areas of steppes, semideserts or deserts, sandy coasts and dunes, areas of sparse tufted vegetation, bare sandy or stony soils with scattered scrubs, dry hillsides, river banks, desert edges with scrubs (Harrison, 1982).

Melanocorhypha calandra Linnaeus, 1766 (Pl. 3, Fig. 5). Lark-like morphology of distal tmt was dimensionally closer to the largest European lark, calandra lark. Melanocorhypha calandra is known from the EP to LP of numerous Eurasian localities from Spain to Russia and Israel (Tyrberg, 1998; 2008). The locality falls within the recent breeding range of the species (Hagemeijer \& Blair, 1997). Occurs mainly in drier warmer grass steppes in lowland areas, grass steppes with some tall herbage, shrubby growths, feathergrass and short Artemisia and arable grounds (Harrison, 1982).

Melanocorhypha sp. Melanocorhypha larks were widely spread throughout Europe during the Pleistocene (Tyrberg, 1991), including the Balkans (Boev, 2001b).

Alauda sp. (Pl.3, Fig. 2). The two distal humeri were bigger than these of Lullula and Calandrella and smaller than the ones of Melanocorypha and Galerida and resembled most to Alauda in size and shape. Finds of Alauda sp. are known from the LP from France, Germany, f. Czechoslovakia and Ukraine
(Tyrberg, 1998; 2008). In Greece, the genus Alauda has not yet been established in the fossil records (Tyrberg, 1998).

Lulula arborea (Linnaeus, 1758) (Pl. 3, Fig. 4). The distal end of tmt showed the features (dimensions and structure) of a woodlark. The specimen was compared with all European larks. Known from the EP of Spain; the MP of France, Italy, Romania, Spain and the LP of Belarus, Bulgaria (cf.), f. Czechoslovakia, France, Italy, Poland, Romania, Spain, the U.K. and Ukraine (Tyrberg, 1998; 2008). Recently found in the LP in Mališina Stijena (Montenegro; Bogoćević \& Dimitriević, 2004). The species has not been previously established in the fossil records of Greece. The locality lies within the breeding range of the species (Hagemeijer \& Blair, 1997). Occurs mainly in thin or open birch or oak forests, heathlands with scattered trees, or bordering forests, dry hill slopes (Harrison, 1982). The last author notes that the species is sensitive to small climatic changes, which determines the northern limits of the range.

\section{Hirundinidae Vigors, 1825}

cf. Hirundo sp. (Pl. 3, Fig. 6). The only find (distal ulna fragment) was compared with all European swallows and resembled most to Hirundo/Cercopis. Its fragmentarity excluded further identification. Finds of g. Hirundo are widely known from the EP to LP from Belarus to Spain and from the United Kigdom to Kirgizia (Tyrberg, 1998; 2008). In Greece, the Hirundo swallows have been established in Vraóna (H. rustica) and in the Liko Cave ( $H$. daurica). Recently, $H$. daurica (now Cecropis daurica (Laxmann, 1769) has been found in the LP of Mališina Stijena (Montenegro; Bogoćević \& Dimitriević, 2004). The locality lies within the recent breeding ranges of these species (Hagemeijer \& Blair, 1997). Occurs in a broad range of habitats: from drier mountains to grassy areas, near water in lowlands and valleys (Harrison, 1982).

Riparia/ Ptyonoprogne (Pl. 3., Fig. 7) cf. Riparia riparial Ptyonoprogne rupestris. The only find (a distal end of tarsometatarsus) was compared with all European swallows and resembles most to Riparia riparia and Ptyonoprogne rupestris. Its fragmentarity excluded further identification. Finds of Riparia and Ptyonoprogne are known from the MP from France to China, from the LP of Belarus to Egypt and from Spain to Georgia (Tyrberg, 1998; 2008). These genera have not been previously established in the fossil records of Greece. The locality lies within the recent breeding range of Riparia riparia and Ptyonoprogne rupestris (Hagemeijer \& Blair, 1997). It occurs in a 
broad range of habitats: from sandy estuaries and seacoast banks to rocky outcrops and cliffs and drier mountain slopes (Harrison, 1982).

\section{Motacillidae Vigors, 1825}

Anthus sp. (cf. A. trivialis) (Pl. 3, Fig. 8). The only find (a distal end of tarsometatarsus) was compared with most of the European wagtails and pipits and resembles most to the tree pipit, but further determination would have been speculative. The find was strongly elongated and typical for g. Anthus. Remarks: Anthus sp. is known from the MP to LP of $\mathrm{f}$. Czechoslovakia, Georgia, Italy, Belgium, Switzerland, Hungary and Uzbekistan (Tyrberg, 1998; 2008). The water/rock pipit complex (A. spinoleta/petrosus) is considered "montane" element in the LP deposits throughoout Europe (Tyrberg, 1991). Recently, A. cf. campestris has been found in LP of Mališina Stijena (Montenegro; Bogoćević \& Dimitriević, 2004). In Greece, the genus Anthus has not been established in the fossil record so far (Tyrberg, 1998). Pipits occur both in areas of open and scattered trees and shrubs and/or open treeless habitats (Harrison, 1982).

\section{Bombycillidae Swainson, 1831}

Bombycilla garrulus (Linnaeus, 1758) (P1. 3, Fig. 9). The only find (a distal end of tarsometatarsus) showed clear similarity to the waxwing. The shape and position of foramen vascular distale and the extensor groove, as well as the deeper relief of the three trochleae completely fitted the description of $B$. garrulus. Known from the MP of France and from the LP of Bosnia-Herzegovina, Croatia, $f$. Czechoslovakia, France, Hungary, Italy, Poland, Romania and the United Kingdom (Tyrberg, 1998; 2008). So far, the species has not been established in the fossil records of Greece. The locality lies outside of the recent breeding range of the species, but falls within its present wintering range (Hagemeijer \& Blair, 1997). It occurs mainly in thick conifer or mixed forests with a berry-bearing shrub layers, riverbanks, forest tundra. In the wintertime accomplishes irruptive movements (Harrison, 1982).

\section{Cinclidae Sundevall, 1836}

Cinclus cinclus (Linnaeus, 1758) (Pl. 3, Fig. 10). All pedal phalanges were distal (claw) phalanges and bore specific features for the dipper, i. e. high and compressed phalangeal body, deep lateral grove and deep relief of the articular facies. The similarity with C. cinclus was unequivocal. Known from the MP of Germany and France and from the LP from the U.K. to Belarus and from Germany to Romania (Tyrberg, 1998; 2008). So far, the species has not been established in the fossil records of Greece. The locality lies within the recent breeding range of the species (Hagemeijer \& Blair, 1997). It occurs near clear running waters, mainly with a stony or gravelly bed and usually around rocky mountain streams and small rivers (Harrison, 1982).

Turdidae Bonaparte, 1838 (Pl. 4, Fig. 1). This find was heavily damaged. Morphologically resembled to g. Turdus and dimensionally was closer to $T$. viscivorus. In all remaining European thrushes tmt is smaller. Known from the EP to LP from numerous Eurasian localities from Spain to Russia and Iraq (Tyrberg, 1998; 2008). In Greece, the species is known from the LP of the Kitsos Cave (Attiki) (Tyrberg, 1998). Remains of Turdus pilaris/viscivorus have been found in the Liko Cave (Crete) (Tyrberg, 2008). The locality falls within the recent breeding range of the species (Hagemeijer \& Blair, 1997). Turdus viscivorus occurs mainly in mature open forests with little undergrowth, in mountain forests and in winter more frequently in open grasslands (Harrison, 1982).

Turdus sp. The bone fragment was so damaged, that even generic identification was difficult. Although it was heavily damaged, dist. epiphysis of the tmt was typical for g. Turdus. In Greece, remains of Turdus sp. are known from the LP of the Klissoura Cave I (Argolis) (Tyrberg, 2008; Bochenski \& Tomek, 2010); the ?LP of Gumbes B, the Liko Cave (both in Crete) and the LP of the Tylos Island (Tyrberg, 1998; 2008).

\section{Sylviidae Vigors, 1825}

Sylvia sp. cf. S. borin (Boddaert, 1783) (Pl. 4, Fig. 2). The only and fragmentary find of a tiny distal tmt was compared with most of European Sylvia warblers and the kinglets; the preserved features allowed referring it only to g. Sylvia. Known from the MP of the U.K. and from the LP of Croatia and Israel (Tyrberg, 1998; 2008). The species has not been previously established in the fossil records of Greece. The locality lies within the recent breeding range of the species (Hagemeijer \& Blair, 1997). Occurs mainly in the shrubby undergrowth in mixed and broadleaf forests, clearings, birch scrubs; in the southern parts of its range occurs mainly in mountain forests (Harrison, 1982).

\section{Muscicapidae Vigors, 1825}

Phoenicurus sp. cf. P. ochruros (S. G. Gmelin, 1774) (Pl. 3, Fig. 11). The only find (a distal ulna) was typical for the smaller muscicapids of Saxicolinae and Erithacinae, but higher resemblence was established 
with the redstarts. Known from the LP of Austria and Israel (Tyrberg, 1998; 2008). The locality lies within the recent breeding range of the redstarts (Hagemeijer \& Blair, 1997). Occurs mainly in the forested mountains, vegetated areas, groves, even rock outcrops (Harrison, 1982).

Erithacus/ Luscinia (Pl. 3, Fig. 12). The only find was a distal tmt which was compared with species of all European genera of smaller muscicapids. The distal epiphysis was much similar than that of Erithacus/Luscinia. Erithacus rubecula has been found in some ?LP layers of the deposits in the Liko Cave (Crete) (Tyrberg, 2008). Erithacus and Luscinia are known from the EP of Spain and $\mathrm{f}$. Czechoslovakia and from the LP from the U.K. to Georgia and Israel. Erithacus rubecula is known from the LP of the Liko Cave (Tyrberg, 1998; 2008). The locality lies within the resent breeding range of the $E$. rubecula (Hagemeijer \& Blair, 1997). The species of the Erithacus-Luscinia complex occur in thick forests with shrubby undergrowth, marshy areas, clearings, in stunted conifers and birch zones, alpine meadows and lowland areas and on hills usually in broadleaf forests (Harrison, 1982).

\section{Paridae Vigors, 1825}

Parus major Linnaeus, 1758 (Pl. 4, Fig. 3). The only find was a distal tmt which was compared with species of all European tits. Dimensionally and morphologically completely fitted to the great tit. Known from the EP of Romania, Spain and Ukraine; the MP of Austria and China and from the LP between the U.K. and Ukraine (Tyrberg, 1998; 2008). The locality lies within the recent breeding range of the species (Hagemeijer \& Blair, 1997). Occurs mainly in the broadleaf forests, but also in conifer or mixed forests and groves (Harrison, 1982).

\section{Sittidae Lesson, 1828}

Sitta cf. europaea Linnaeus, 1758 (P1. 4, Fig. 4). The only find was a complete claw phalanx of the third (largest) toe. It was thinner and longer and all other features entirely matched those of the corresponding skeletal element of the Eurasian nuthatch. Known from the EP of Austria; the MP of f. Czechoslovakia and the U.K. and from the LP of Austria, Bulgaria, Croatia, Switzerland, France, Poland, f. Czechoslovakia and Romania (Tyrberg, 1998; 2008). The locality lies within the recent breeding range of the species (Hagemeijer \& Blair, 1997). Occurs mainly in broadleaved, mixed or conifer forests; often in well-grown more open forests with tall trees, mainly in the mountains but also in the open hillside forests (Harrison, 1982).

Sitta sp. The lateral condyle of tr. m. III wider than in S. europaea. Nuthatches are common in many Late Pleistocene localities in Europe, including neighbouring Bulgaria (Boev, 2001b).

\section{Corvidae Vigors, 1825}

Garrulus glandarius (Linnaeus, 1758) (Pl. 4, Fig. 7). The finds (pedal phalanges and a fragmentary distal tmt) had morphology and size of larger passeriform (corvids). Corvus, Pyrrhocorax and Nucifraga are bigger, while Cyanopica and Perisoreus are smaller. It differed from Pica pica in the shorther phalangeal body and completely fited the Eurasian Jay. Known from numerous Eurasian localities from Spain to China (Tyrberg, 1998; 2008). In Greece, the species is known from the ?LP of Gerani II (Crete), Gumbes B (Crete), Gumbes C (Crete), the Liko Cave (Crete), Mavro Mouri (Crete); the LP of Tylos (Tyrberg, 1998; 2008) and (cf.) from the LP of the Klissoura Cave 1 (Bochenski \& Tomek, 2010). The locality falls within the recent breeding range of the species (Hagemeijer \& Blair, 1997). Occurs mainly in broadleaf forests with oak, mixed and conifer forests and riverine forests (Harrison, 1982).

Pica pica (Linnaeus, 1758) (Pl. 4, Fig. 8). Known from the EP to LP from numerous Eurasian localities from Spain to Lebanon, Israel and China (Tyrberg, 1998; 2008). Recently found in the LP of Mališina Stijena (Montenegro; Bogoćević \& Dimitriević, 2004). In Greece, the species is known from the LP of the Kalamakia Cave (Lakonia) (Tyrberg, 2008). The locality falls within the recent breeding range of the species (Hagemeijer \& Blair, 1997). Occurs mainly in open areas and scrubs with taller dense trees or shrubs, open forests, clearings, heathlands, scrubs on hills and mountains, semideserts, tall shrubs, forest tundra (Harrison, 1982).

Pica sp. The find (Fig. 3) is dimensionally smaller than $C$. monedula Linnaeus, 1758, $P$. graculus, $P$. pyrrhocorax and bigger than $N$. caryocatactes, P. pica, C. cooki and G. glandarius (Table 4). According dos Anjos (2009), P. infaustus is the smallest European corvid in terms of body length and mass, except for C. cooki (Table 5), but this species has not been compared. Pica pica is the most similar species but LAC B13 differed from it by its larger size. From N. caryocatactes it differed by the better developed narrowing ("neck") of prox. end and the much shallower longitudinal concavity on the dorsal surface of the bone. LAC B13 differed from $P$. pica by the relatively longer "neck" of prox. end. 
On the other hand, morphologically it significantly resembled $P$. pica but was much bigger in size. From $C$. monedula it differed by the steeper (sharper) widening after "neck" and the shallower relief of the dorsal surface. LAC B13 specimen was compared with the measurements of the European corvids (Tomek \& Bochenski, 2000). It did not fit to any of the 662 European specimens of corvids, measured by Tomek \& Bochenski (2000: Table XII, p. 50), including $P$. infaustus. As seen in Table 4, the measurement "a" much approached only to the maximum value of $N$. caryocatactes (13.9), the measurement " $\mathrm{b}$ " lied within the ranges of $P$. pica (3.2-4.9), P. graculus (3.7-5.1) and C. monedula (4.25.1 ), the measurement "c" lied within the ranges of $G$. glandarius (2.2-3.0), P. pica (2.3-3.0), P. graculus (2.7-3.7) and $C$. monedula (2.9-3.6), whereas the measurement "d" lied within the ranges of $P$. graculus (2.1-2.2) and C. monedula (1.8-2.4). In comparison with these species, LAC B13 specimen differed from: C. monedula by the much smaller (shorter) phalanx (measurement "a") and the more angular ventral end of distal f. a.; P. pica by the bigger size, thinner ventral edge on the medial side and the better developed pila cranialis; P. graculus by the much smaller size and the relatively thicker "neck" in the proximal end; G. glandarius and C. cooki by the much bigger size. Index "total length: proximal width" (Table 4) of B13 was 3.404, whereas for P. pica it was 3.378. This was the smallest difference when compared to the values of this index among other small corvids in Europe: C. cooki - 3.076; G. glandarius - 3.171, N. caryocatactes - 3.500, P. infaustus - 3.520, P. pyrrhocorax - 3.627, C. monedula - 3.630 and Pyrrhocorax graculus - 3.638.

Mlíkovský (2002) synonymised Pica pica major Janossy 1972 from Stránská Skála I (Czechia) with $C$. monedula. After the original diagnosis of D. Janossy, skeletal elements of this subspecies were bigger than those of the modern European magpie. Pica p. major originates from Southern Czechia (Stránská skála) and is dated to EP (MQ 1b) (Mlíkovský, 2002). Although the total length of the humerus and femur of $P . p$. major exceeds these measurements in modern $P$. pica (by $13.52 \%$ and $13.83 \%$, respectively; calculations after measurements of Janossy, 1972), because of the lack of analogous skeletal elements for comparison and the considerable chronostratigraphical difference (ca. 0.6 Ma), we prefer to designate the EEH magpie from the Loutra Almopias Cave to Pica sp. and not to refer it tentatively to the $P$. p. major (even less so to C. monedula after Mlíkovský, 2002).

Pyrrhocorax graculus (Linnaeus, 1766) (Pl. 4, Fig. 10). The Alpine chough was the most numerous species among the material. All skeletal elements bore the features of a large passeriform and both morphologically and dimensionally resembled completely $P$. graculus. Known from the EP to LP of numerous Eurasian localities from Spain to Israel, Georgia and Azerbaijan (Tyrberg, 1998; 2008). Recently found in the LP of Mališina Stijena (Montenegro; Bogoćević \& Dimitriević, 2004). In Greece, the species is known from the LP of Elaiochoria (Chalkidiki); the ?LP of Gerani IV (Crete) and of the Liko Cave (Crete) and the LP of Vraóna (Attiki) (Tyrberg, 1998; 2008). The locality falls within the recent breeding range of the species (Hagemeijer \& Blair, 1997). Occurs mainly in areas where steep rocky slopes adjoin open grasslands in the mountains (Harrison, 1982).

Pyrrhocorax cf. pyrrhocorax (Linnaeus, 1758) (Pl. 4, Fig. 9). All finds (distal tmt and pedal phalanges) represented large passerines (corvids). The size and robustness of the tmt-fragment distinguished it from $P$. graculus and completely fitted to the redbilled chough. Widely known from the EP to LP of numerous Eurasian localities from Portugal to China (Tyrberg, 1998; 2008). In Greece, the species is known from the LP of Vraóna (Attiki) and of the Tylos; the?LP of the Liko Cave (Crete) (Tyrberg, 1998; 2008), (cf.) from the LP of the Klissoura Cave 1 (Bochenski \& Tomek 2010). The locality lies outside (but not very remote; ca. $150 \mathrm{~km}$ away) the recent breeding range of the species (Hagemeijer \& Blair, 1997). It occurs mainly in areas where steep cliffs and crags occur close to open grassy areas in the mountains (Harrison, 1982).

Pyrrhocorax sp. (P. graculus/pyrrhocorax). Eight fragmentary bone pedal phalanges had been collected. Their size and morphology indicated Pyrrhocorax sp.

Corvidae gen. indet. - 1. Complete, intact. Resembles $P$. graculus, but the phal. body was thicker.

Corvidae gen. indet. - 2. Dimensionally close to C. monedula and P. graculus, but the shape of cotyla humeralis was elliptical instead round. Dimensions of the specimen B 342 lied within the ranges of three species: C. monedula, $P$. graculus and $P$. pyrrhocorax (Table 6) after data of Tomek \& Bochenski (2000). On the other hand, morphologically this specimen differed from P. pyrrhocorax by the elliptical shape of cotyla humeralis and the slender shaft (diaphysis). It differed from $P$. pica by the elliptical shape of cotyla humeralis and the rounder instead angular section of the proximal diaphysis. From C. monedula it also differed by the elliptical shape of cotyla humeralis and the more uprised tuberculum bicipitale. From $N$. caryocatactes it differed by the elliptical shape of cotyla humeralis, more uprised tuberculum bicipitale and the rounder instead angular section of the proximal diaphysis. 
cf. Corvidae gen. indet. Only the dist. fourth of the wing ph. prox. d. majoris dex. was preserved. Size of G. glandarius but further identification was not possible.

\section{Sturnidae Vigors, 1825}

Sturnus sp. cf. S. vulgaris Linnaeus, 1758 (Pl. 4, Figs. 5-6). Known from the EP to LP of numerous Eurasian localities from Spain to Russia, Israel and Iraq (Tyrberg, 1998; 2008). In Greece, the species is known from the LP of the Kitsos (Attiki) (Tyrberg, 1998). Remains of Sturnus sp. are known from the ? LP of the Liko Cave (Crete) (Tyrberg, 2008). Recently found in the LP of Mališina Stijena (Montenegro; Bogoćević \& Dimitriević, 2004). The locality falls within the recent breeding range of the species (Hagemeijer \& Blair, 1997). Occurs in open montane forests with grassy clearings, riverine forests in meadows and groves (Harrison, 1982). Probably most of the material belonged to $S$. vulgaris, but due to the higher morphological resemblance of both species and the preservation of the finds, it could be further identified. Theoretically, part of the identified material could belong to $S$. roseus (Linnaeus, 1758), a species hardly distinguishable osteomorphologically from the common starling. The rosy starling was also regularly found in the Würmian deposits of Europe (Tyrberg, 1991).

\section{Fringillidae Vigors, 1825}

Fringilla sp. cf. F. coelebs Linnaeus, 1758 (Pl. 5, Fig. 2 ). The find (proximal part of a humerus) closely resembled, in terms of the shape of crista pectoralis, tuberculum ventral and caput humeri, to the common chaffinch. Known from numerous Eurasian localities from Spain to China (Tyrberg, 1998; 2008). Remains of Fringilla coelebs/montefringila have been reported from the ?LP of the Liko Cave (Crete) (Tyrberg, 2008). The locality falls within the recent breeding range of the species (Hagemeijer \& Blair, 1997). Occurs mainly in the more open and marginal areas of all types of forest and small woodlands (Harrison, 1982).

Carduelis sp. cf. C. carduelis (Linnaeus, 1758) (Pl. 4. Fig. 12). Carduelis carduelis is known from the EP to LP of a number of Eurasian localities from Spain to Ukraine and Israel (Tyrberg, 1998; 2008). The species has not been previously established in the fossil records of Greece (Tyrberg, 1998). The locality falls within the recent breeding range of the species (Hagemeijer \& Blair, 1997). Occurs mainly in the open-foliaged broadleaved trees, weed-grown grounds or mixed herbages, edges and clearings of forests, scattered groups of trees, steppes, riverine forests, shrubs and groves (Harrison, 1982).

cf. Chloris chloris (Linnaeus, 1758) (Pl. 5, Fig. 1). The similarity of these fragmentary find of a proximal $\mathrm{cmc}$ (synostosis metacarpalis prox.) was highest to the European creenfinch. Known from the EP and MP of France and Israel, the MP of Malta and from the LP from France to Israel and from the U.K. to Ukraine. Recently found in the LP of Mališina Stijena (Montenegro; Bogoćević \& Dimitriević, 2004). In Greece, the species has been found in the LP deposits of the Liko Cave (Tyrberg, 1998; 2008). The locality lies within the recent breeding range of the species (Hagemeijer \& Blair, 1997). Occurs mainly in the open-foliaged broadleaved forests. This species prefers tall and well-grown trees (Harrison, 1982).

Carduelis sp. The specimen (tmt dex. dist.) was slightly bigger than $C$. spinus but identification to the species level was not possible.

Loxia curvirostra Linnaeus, 1758 (Pl. 5., Fig. 5). Known from the MP to LP of a number of Eurasian localities from France to Russia and Israel (Tyrberg, 1998; 2008). The species has not been previously established in the fossil records of Greece (Tyrberg, 1998). The locality lies outside of the recent breeding range of the species, but it frequently inhabits the Pindos and Rhodopes Mountains in N Greece (Hagemeijer \& Blair, 1997). Occurs mainly in conifer (spruce) forests, mixed forests and mountain forests (Harrison, 1982).

Coccothraustes coccothraustes (Linnaeus, 1758) (Pl. 5, Fig. 4). Known from the EP to LP of numerous Eurasian localities from Spain to Israel and China (Tyrberg, 1998; 2008). In Greece, the species is known from the ?LP of the Liko Cave (Crete) (Tyrberg, 1998; 2008). The locality falls within the recent breeding range of the species (Hagemeijer \& Blair, 1997). Occurs mainly in broadleaf and mixed forests, riverine forests, forest steppes, groves, scattered tall trees and open areas (Harrison, 1982).

Pyrrhula pyrrhula (Linnaeus, 1758) (Pl. 5, Fig. $3)$. Various skeletal elements were found among the material: mandibulae, humeri, os quadratum and tarsometatarsi. The proximal (articular) fragment of the mandible for example was rather diagnostic with its high ramus mandibulae (in the region of os praearticulare). Known from the MP to LP of a number of Eurasian localities from Spain to Greece (Tyrberg, 1998; 2008). Recently found in the LP of Mališina Stijena (Montenegro; Bogoćević \& Dimitriević, 2004). In Greece, the species is known from the ?LP of the Liko Cave (Crete) (Tyrberg, 1998; 2008). The locality falls within the recent breeding range of the species (Hagemeijer \& Blair, 1997). Occurs mainly in conifer and mixed forests and 
broadleaf forests with thick undergrowth (Harrison, 1982).

Fringillidae gen. indet. Similar to Fringilla coelebs size but further identification was not possible.

\section{Emberizidae Vigors, 1831}

Emberiza calandra Linnaeus, 1758 (P1. 5, Figs. 8-9). The finds were compared with most of the European buntings. The corn bunting is the largest among them and the distal tmt and clow phalanx fully fitted in size and shape of that species. Known from the LP of Israel, Spain, Framce, Germany and Greece (Liko Cave, Crete) (Tyrberg, 2008). The locality falls within the recent breeding range of the species (Hagemeijer \& Blair, 1997). In Greece, this species has been established in the LP deposits of the Liko Cave. Occurs mainly in open grassy areas with some tall herbage or low shrubs, in the vegetation of dry and semiarid regions, grass steppes with sparse shrub, stony steppes with sparse herbage, grassy areas of sandy desert, hilly steppe areas (Harrison, 1982).

cf. Plectrophenax nivalis (Linnaeus, 1758) (Pl. 5, Fig. 7). Seven distal tmt were identified. Known from the MP of France and Ukraine, from the LP from the U.K. and France to Italy and Ukraine (Tyrberg, 1998; 2008). The snow bunting has not been previously established in the fossil records of Greece. The locality lies outside both of the recent breeding and wintering range of the species. On the Balkans, the species has been recorded as an accidental winter visitor in Bulgaria, f. Yugoslavia (Cramp \& Perrins, 1994) and Greece (Anonym, 2018). Breeds on bare rocky tundra but winters on the stony or sandy shores and dunes of low-laying coastal areas, grass moorlands and grass steppes (Harrison, 1982).

Emberiza sp. cf. E. cirlus Linnaeus, 1766 (P1. 5, Fig. 6). Known from the LP sites of Croatia, Italy and Spain (Tyrberg, 1998; 2008). Previously, the species has not been established in the fossil records of Greece. The locality lies within the recent breeding range of the species (Hagemeijer \& Blair, 1997). Occurs mainly in grassy hillsides with scattered trees, open broadleaf forests and groves (Harrison, 1982).

Emberizidae gen. indet. (size of Plectrophenax nivalis). The LAC B 173 bone fragment was so damaged that even generic identification would be impossible, although it demonstrated some resemblance in terms of size and morphology with the buntings (and especially with Plectrophenax nivalis).

Oscines Non-Corvidae indet. The 25 specimens identified as Oscines N-Corvidae indet. differed from Sturnus, Turdus, Monticola and Corvidae. Most of them represented pedal phalanges and fragmentary tarsometatarsi of small, unidentifiable Passerines.

Non-Passeriformes indet. The LAC B 55 specimen represented an articular (prox.) half of a large claw $\mathrm{ph}$. with extremely deep grows on its lateral sides. Further identification was not possible.

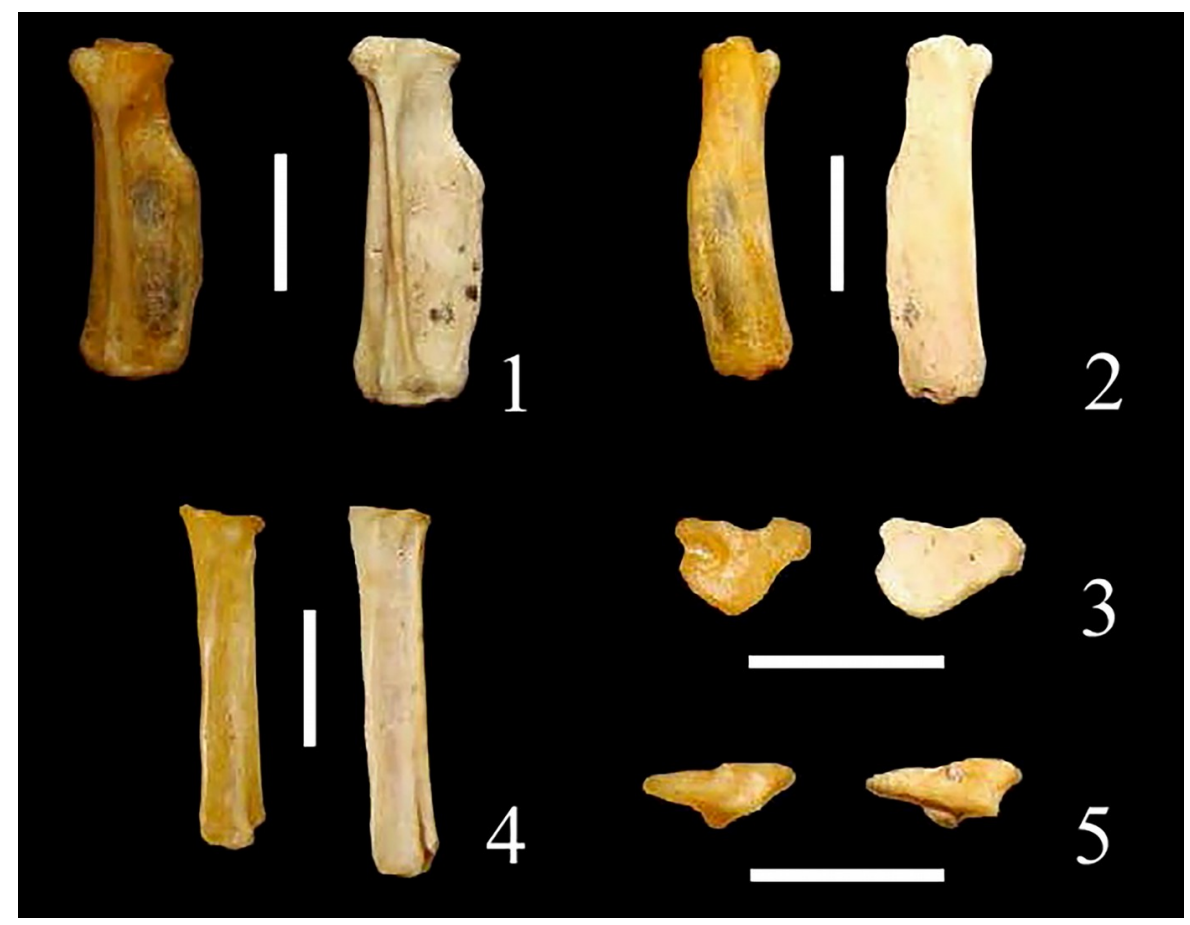

Fig. 3. Ph. prox. d. majoris dex. of Pica pica pica (Linnaeus, 1758), NMNHS 5/1989, Ravno Pole, Near Sofia, Bulgaria, recent (left), and Pica sp., B 13, Loutra Almopias Bear Cave, Macedonia, Greece, EEH (right) (scale bar 5 mm): lateral view (1); medial view (2); cranial view (3); dorsal view (4); caudal view (5). 
Table 1. Taxonomic and chronostratigraphic distribution of the Quaternary avian finds of the Loutra Almopias Cave (LAC), Northern Greece. The presence +/absence - of each taxon is shown locally (Voras Mountain region) and nationally (Greece), as well as the population status of each species in Greece (where applicable): RS, resident;

SM, summer migrant; WM, winter migrant; EX, regionally extinct. Other abbreviations: NISP: Number of Identified Specimens.

\begin{tabular}{|c|c|c|c|c|c|}
\hline \multirow[b]{2}{*}{$\begin{array}{l}\text { Taxa and recent species' population } \\
\text { status in Greece }\end{array}$} & \multicolumn{2}{|c|}{ LAC Sites } & \multirow[b]{2}{*}{ Total NISP } & \multirow[b]{2}{*}{$\begin{array}{c}\text { Voras } \\
\text { Mt. }\end{array}$} & \multirow[b]{2}{*}{ Greece } \\
\hline & $\begin{array}{l}\text { Late } \\
\text { Pleisto- } \\
\text { cene }\end{array}$ & $\begin{array}{c}\text { Earliest } \\
\text { Holocene }\end{array}$ & & & \\
\hline GALLIFORMES & & & 153 & & \\
\hline Phasianidae & & & 143 & & \\
\hline Perdix perdix (RS) & 2 & 51 & 53 (42 cf.) & - & + \\
\hline Perdix sp. & 2 & 3 & 5 (3 cf.) & - & + \\
\hline Alectoris graeca (RS) & 1 & 45 & 46 (41 cf.) & + & + \\
\hline Alectoris sp. & 3 & 19 & 22 (15 cf.) & + & + \\
\hline Francolinus francolinus (EX) & - & 2 & 2 & - & - \\
\hline Francolinus sp. & - & 1 & 1 & - & - \\
\hline Alectoris/Francolinus & - & 2 & 2 & + & $?$ \\
\hline Perdix/Francolinus & - & 5 & 5 & - & $?$ \\
\hline Perdicinae gen. & - & 7 & 7 & + & + \\
\hline Tetraonidae & & & 10 & & \\
\hline Tetrao tetrix $(\mathrm{EX})$ & - & 2 & 2 & - & - \\
\hline Lagopus cf. lagopus (EX) & 2 & 1 & 3 & - & - \\
\hline aff. Lagopus sp. & - & 1 & 1 & - & - \\
\hline cf. Bonasa bonasia (RS) & 1 & - & 1 & + & + \\
\hline Bonasa bonasia/ Lagopus muta & - & 3 & 3 & + & $?$ \\
\hline COLUMBIFORMES & & & 35 & & \\
\hline Columbidae & & & 35 & & \\
\hline Columba livia (RS) & 1 & 21 & 22 (1 cf.) & - & + \\
\hline Columba palumbus (RS) & 2 & 11 & 13 (10 cf.) & + & + \\
\hline CAPRIMULGIFORMES & & & 1 & & \\
\hline Caprimulgidae & & & 1 & & \\
\hline ? Caprimulgus sp. (SM) & - & 1 & 1 & + & + \\
\hline ACCIPITRIFORMES & & & 1 & & \\
\hline Accipitridae & & & 1 & & \\
\hline Buteo sp. cf. B. lagopus (WM) & - & 1 & 1 & - & - \\
\hline FALCONIFORMES & & & 23 & & \\
\hline Falconidae & & & 23 & & \\
\hline Falco sp. cf. F. peregrinus (RS) & 1 & 2 & 3 & + & + \\
\hline Falco sp. ex gr. F. cherrug & - & 1 & 1 & + & + \\
\hline Falco sp. cf. tinnunculus (RS) & - & 13 & 13 & + & + \\
\hline Falco sp. cf. vespertinus (EX) & - & 5 & 5 & + & - \\
\hline Falco sp. ex gr. tinnunculus & - & 1 & 1 & + & + \\
\hline STRIGIFORMES & & & 10 & & \\
\hline
\end{tabular}


Strigidae

Bubo bubo (RS)

Athene noctua (RS)

cf. Otus scops (SM)

PICIFORMES

Picidae

cf. Dryocopus martius (RS)

cf. Picidae

PASSERIFORMES

Alaudidae

Galerida sp. cf. G. cristata (RS)

Melanocorhypha calandra (RS)

Melanocorhypha sp.

Alauda sp. (RS)

Lulula arborea (RS)

Hirundinidae

cf. Hirundo sp. (SM)

Riparia/ Ptyonoprogne (SM)

Motacillidae

Anthus sp. (SM/WM/RS)

Bombicyllidae

Bombicylla garrulus

Cinclidae (WM)

$\begin{array}{ll}3 & 5 \\ - & 1 \\ - & 1\end{array}$

10

8

$1++$

1 (1 cf.)

2

2

1 (1 cf.) + +

1 (1 cf.) + +

306

15

4

4 ( 2 cf.) - $\quad+$

$2 \quad-\quad+$

$2++$

$3(1 \mathrm{cf})+\quad+$

Cinclus cinclus (RS)

Turdidae

Turdus sp. cf. T. vuscivorus (RS)

Turdus sp.

Sylviidae

Sylvia sp. cf. S. borin (SM)

Muscicapidae

Phoenicurus sp. cf. P. ochruros

(RS/WM)

Erithacus / Luscinia (RS/WM)

Paridae

Parus major

Sittidae

Sitta cf. europaea (RS)

Sitta sp.

Corvidae

Garrulus glandarius (RS)

Pica pica (RS)

Pica sp.

Pyrrhocorax graculus (RS)

Pyrrhocorax cf. pyrrhocorax (RS) 
Pyrrhocorax sp.

(P. graculus/pyrrhocorax)

Corvidae gen. - 1

Corvidae gen. - 2

cf. Corvidae gen.

Sturnidae

Sturnus sp. cf. S. vulgaris (RS)

Fringillidae

Fringilla sp. cf. F. coelebs (RS)

Carduelis sp. cf. C. carduelis (RS)

cf. Chloris chloris (RS)

Carduelis sp.

Loxia curvirostra (RS)

Coccothraustes coccothraustes (RS)

Pyrrhula pyrrhula (RS)

Fringillidae gen.

Emberizidae

Emberiza calandra (RS)

cf. Plectrophenax nivalis (EX)

Emberiza sp. cf. E. cirlus (RS)

Emberizidae gen.

Oscines Non-Corvidae indet.

Non-Passeriformes indet.

Totals

$\begin{array}{ccccc}- & 9 & 9(4 \text { cf. }) & + & + \\ - & 1 & 1 & + & + \\ - & 1 & 1 & + & + \\ - & 1 & 1 & + & + \\ - & 4 & 4(2 \text { cf. }) & + & +\end{array}$

58

$\begin{array}{ccc}1 & + & + \\ 1 & + & + \\ 1 & + & + \\ 2(1 \text { cf. }) & + & + \\ 20(7 \text { cf. }) & - & + \\ 22(8 \text { cf. }) & + & + \\ 8(4 \text { cf. }) & + & + \\ 3(2 \text { cf. }) & + & +\end{array}$

13

3 (2 cf.)

7 (7 cf.)

1 (1 cf.)

2 (1 cf.)

15

5

415509

551

$47 \quad 60$

Table 2. Measurements (in mm) of coracoids of fossil and recent galliforms (ref. to Fig. 2-A).

\begin{tabular}{lrrrr}
\hline \multicolumn{1}{c}{ Species } & a & b & c & d \\
\hline \multicolumn{1}{c}{ Recent } & & & & \\
\hline Francolinus francolinus LAC B 150, Loutra Almopias Cave & 7.37 & 2.40 & 1.93 & 2.16 \\
\hline Francolinus francolinus - SFINM 7632 & & & & \\
Alectoris rufa NMNHS 1/1992 Spain & 7.62 & ca. 2.46 & - & 2.21 \\
Alectoris graeca NMNHS 1/1986 SW Russia & 8.09 & 3.42 & 3.25 & 3.24 \\
Alectoris graeca NMNHS 3/1989 Bulgaria & 7.65 & 3.60 & 3.15 & 3.24 \\
Alectoris graeca NMNHS 4/2002 Bulgaria & 8.37 & 3.64 & 3.16 & 3.20 \\
Alectoris chukar NMNHS 3/1990 Bulgaria & 8.14 & 3.54 & 3.10 & 3.31 \\
Alectoris chukar NMNHS 4/1990 Bulgaria & 8.18 & 3.44 & 2.32 & 3.03 \\
Perdix perdix NMNHS 2/1983 Bulgaria & 8.14 & 3.17 & 2.81 & 3.00 \\
Perdix perdix NMNHS 4/1989 Bulgaria & 9.47 & 3.16 & 2.77 & 3.08 \\
Coturnix coturnix NMNHS 10/1989 Bulgaria & 9.79 & 3.02 & 2.48 & 3.00 \\
Coturnix coturnix NMNHS 13/1989 Bulgaria & 5.48 & 1.79 & 1.64 & 1.53 \\
Lagopus mutus NMNHS 2/2000 Sweden & 5.12 & 1.90 & 1.59 & 1.62 \\
Loagopus lagopus NMNHS 1/1986 - Chukotka (Russia) & 11.01 & 3.30 & 2.37 & 3.50 \\
Loagopus lagopus NMNHS 3/2007 Sweden & 13.06 & 3.10 & 2.61 & 4.67 \\
Bonasa bonasia NMNHS 2/2001 Bulgaria & 10.44 & 2.71 & 2,47 & 3.50 \\
Bonasa bonasia NMNHS 3/2002 Bulgaria & - & - & - & 3.49 \\
\hline
\end{tabular}


Table 3. Measurements (in $\mathrm{mm}$ ) of the sternum of fossil and recent galliforms (ref. to Fig. 2-B).

\begin{tabular}{lrrr}
\hline \multicolumn{1}{c}{ Species } & e & f & g \\
\hline \multicolumn{1}{c}{ Fossil } & & & \\
\hline Francolinus francolinus LAC B 163, Loutra Almopias Cave, Greece & 9.92 & 13.69 & 3.65 \\
\hline Francolinus francolinus - SFINM 7632 & & & \\
Alectoris rufa NMNHS 1/1992 Bulgaria & ca. 9.78 & 13.64 & ca. 3.73 \\
Alectoris graeca NMNHS 1/1986 - SW Russia & 16.75 & 12.43 & 3.43 \\
Alectoris graeca NMNHS 3/1989 Bulgaria & 14.13 & 13.80 & 3.76 \\
Alectoris graeca NMNHS 4/2002 Bulgaria & 15.20 & 15.15 & 4.63 \\
Alectoris chukar NMNHS 3/1990 Bulgaria & 15.12 & 13.78 & 4.23 \\
Alectoris chukar NMNHS 4/1990 Bulgaria & 15.81 & 15.00 & 4.10 \\
Perdix perdix NMNHS 2/1983 Bulgaria & 15.07 & 14.02 & 3.94 \\
Perdix perdix NMNHS 4/1989 Bulgaria & 16.40 & 16.02 & 4.03 \\
Coturnix coturnix NMNHS 10/1989 Bulgaria & 15.75 & 16.53 & 3.60 \\
Coturnix coturnix NMNHS 13/1989 Bulgaria & 8.73 & 8.68 & 1.80 \\
Lagopus mutus NMNHS 2/2000 Sweden & 8.33 & 8.65 & 2.28 \\
Loagopus lagopus NMNHS 3/2007 Sweden & 16.74 & 15.31 & 3.85 \\
Bonasa bonasia NMNHS 2/2001 Bulgaria & 15.65 & 15.17 & 3.83 \\
Bonasa bonasia NMNHS 3/2002 Bulgaria & ca. 15.20 & & 3.72 \\
& 15.95 & 15.10 & 3.71 \\
\hline
\end{tabular}

Table 4. Measurements (in mm) (mean after Tomek \& Bochenski, 2000 and specimens of the NMNHS) of ph. prox. d. majoris of male and female European corvids.

\begin{tabular}{cccccc}
\hline Species & N & $\begin{array}{c}\text { Total } \\
\text { length }\end{array}$ & $\begin{array}{c}\text { Proximal } \\
\text { width }\end{array}$ & $\begin{array}{c}\text { Proximal } \\
\text { depth }\end{array}$ & $\begin{array}{c}\text { Distal } \\
\text { depth }\end{array}$ \\
\hline
\end{tabular}

Fossil

Pica sp. - LAC B13 Loutra Almopias Cave, Greece $\quad 1 \quad 14.3 \quad 4.2 \quad 3.0 \quad 2.1$

Recent

\begin{tabular}{|c|c|c|c|c|c|}
\hline$\overline{\text { Corvus corax } \hat{\jmath} \hat{\jmath}+q q}$ & 26 & 32.9 & 8.7 & 6.4 & 3.9 \\
\hline 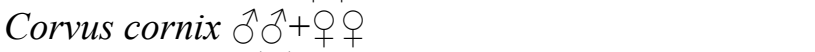 & 39 & 22.0 & 5.3 & 4.4 & 2.7 \\
\hline Corvus corone $\hat{\delta} \hat{\delta}+q+$ & 20 & 21.5 & 6.2 & 4.3 & 2.6 \\
\hline Corvus frugileus $\widehat{\partial} \widehat{\partial}+q++$ & 61 & 21.9 & 6.1 & 4.3 & 2.6 \\
\hline 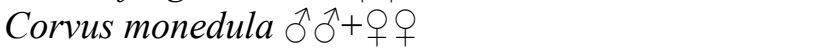 & 42 & 16.7 & 4.6 & 3.3 & 2.0 \\
\hline Corvus monedula NMNHS 10/1991 Bulgaria & 1 & 17.11 & 4.35 & 3.63 & 2.17 \\
\hline Corvus monedula NMNHS 14/2004 Bulgaria & 1 & 15.78 & 4.25 & 3.03 & 1.59 \\
\hline Corvus monedula NMNHS 6/1989 Bulgaria & 1 & 16.81 & 4.72 & 3.50 & 2.33 \\
\hline Corvus monedula NMNHS 9/1989 Bulgaria & 1 & 16.28 & 4.59 & 3.28 & 2.17 \\
\hline Cyanopica cooki $\widehat{\jmath} \hat{o}+q++$ & 2 & 8.0 & 2.6 & 1.8 & 1.2 \\
\hline Cyanopica cooki NMNHS 1/1997 Spain & 1 & 7.78 & 2.64 & 1.84 & 1.21 \\
\hline Garrulus glandarius $\widehat{\jmath}+0++$ & 36 & 11.1 & 3.5 & 2.5 & 1.6 \\
\hline Garrulus glandarius NMNHS 19/2003 Bulgaria & & 10.74 & 3.23 & 2.82 & 1.68 \\
\hline Nucifraga caryocatactes $\widehat{\partial} \delta^{\lambda}+q+$ & 50 & 12.6 & 3.6 & 2.6 & 1.7 \\
\hline Nucifraga caryocatactes NMNHS 10/2002 Bulgaria & 1 & 12.66 & 3.75 & 2.71 & 1.74 \\
\hline Nucifraga caryocatactes NMNHS 7/1984 Bulgaria & 1 & 12.57 & 3.60 & 2.70 & 1.69 \\
\hline Nucifraga caryocatactes NMNHS 9/1984 Bulgaria & 1 & 11.87 & 3.57 & 2.65 & 1.73 \\
\hline Perisoreus infaustus $\widehat{\widehat{\partial}} \widehat{\widehat{O}}+q+q_{+}$ & 10 & 8.8 & 2.5 & 1.9 & 1.3 \\
\hline 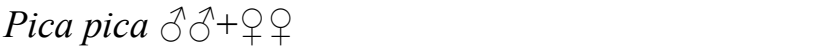 & 47 & 12.5 & 3.7 & 2.7 & 1.6 \\
\hline Pica pica NMNHS 5/1989 Bulgaria & 1 & 12.79 & 3.58 & 2.83 & 1.69 \\
\hline
\end{tabular}


Pica pica NMNHS 7/ 1991 Bulgaria

Pica pica NMNHS 8/1992 Bulgaria

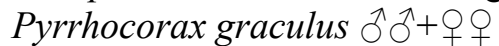

Pyrrhocorax graculus NMNHS 2/1986 Bulgaria

Pyrrhocorax graculus NMNHS 8/2001 Bulgaria

Pyrrhocorax pyrrhocorax ठㅎํ우

Pyrrhocorax pyrrhocorax NMNHS 1/1990 Spain
1

12.23

$1 \quad 12.76$

17

17.1
17.81

18.76

18.5

19

19.56
3.56

3.62

4.7

4.91

5.10

5.1

5.42
2.41

2.70

3.3

3.48

3.88

3.7

4.24
1.56

1.64

2.2

2.47

2.50

2.4 2.66

Table 5. Body measurements of the European smaller corvids (males and females; after dos Anjos, 2009).

\begin{tabular}{lcc}
\hline \multicolumn{1}{c}{ Species } & Body length (mm) & Body mass (g) \\
\hline Perisoreus infaustus Linnaeus, 1758 & $25-31$ & $72-101$ \\
Corvus monedula Linnaeus, 1758 & $34-39$ & $136-265$ \\
Cyanopica cooki Bonaparte, 1850 & $34-36$ & $65-76$ \\
Garrulus glandarius Linnaeus, 1758 & $32-36$ & $150-190$ \\
Nucifraga caryocatactes Linnaeus, 1758) & $32-34$ & $124-220$ \\
Pyrrhocorax graculus Linnaeus, 1766 & $34-38$ & $194-277$ \\
Pyrrhocorax pyrrhocarax Linnaeus, 1758 & $38-41$ & $207-375$ \\
Pica pica Linnaeus, 1758 & $46-50$ & $200-270$ \\
\hline
\end{tabular}

Table 6. Measurements (in mm) (after Tomek \& Bochenski, 2000) of radius prox. of the European smaller corvids.

\begin{tabular}{lcr}
\hline \multicolumn{1}{c}{ Species } & $\begin{array}{c}\text { Range of } \\
\text { proximal } \\
\text { diameter }\end{array}$ & $\begin{array}{r}\text { Height of the } \\
\text { tuberculum } \\
\text { bicipitale }\end{array}$ \\
\hline \multicolumn{1}{c}{ Fossil } & & \\
\hline $\begin{array}{l}\text { Corvidae gen. indet. - LAC B 342, Loutra Almopias } \\
\text { Cave, Greece }\end{array}$ & $2.4-3.4$ & 2.3 \\
& & \\
\hline Perisoreus infaustus & $1.7-2.1$ & 1.3 \\
Garrulus glandarius & $2.3-2.8$ & 1.6 \\
Corvus monedula & $2.4-3.0$ & 2.5 \\
Pica pica & $2.5-2.8$ & 2.0 \\
Nucifraga caryocatactes & $2.2-2.7$ & 1.7 \\
Pyrrhocorax pyrrhocorax & $2.8-3.5$ & 2.6 \\
Pyrrhocorax graculus & $2.5-3.1$ & 2.2 \\
Corvus frugileus & $3.2-4.0$ & 3.0 \\
Corvus corone & $3.1-4.1$ & 2.9 \\
Corvus cornix & $3.3-4.1$ & 3.1 \\
Corvus corax & $4.7-6.0$ & 5.3 \\
Cyanopica cooki & $1.7-2.0$ & 1.4 \\
\hline
\end{tabular}




\section{Discussion}

\section{Taphonomy}

The majority of avian remains recovered in the Loutra Almopias Cave were heavily damaged, usually fragmented. Almost all of the ossa longa tubulosa were broken and mainly epiphyses, or even separate bone splinters (of diaphyses) were present. Sometimes, only fragments of the bone endings were preserved, for example caput humeri, trochlaeae mt., even endings (only f. a.) of the pedal phalanges. In general, for all the collected avian material was characteristic the very high level of fragmentation and complete absence of the traces of erosion. Most numerous were the small/tiny bones as the limb phalanges (mainly pedal), representing $2 / 3$ of the collected material $(67 \%)$. All avian remains (probably with two exceptions) belonged to mature (adult) individuals. Only several juveniles have been recorded among them. On the other hand, over $2 / 3$ of the finds $(73 \%)$ were preserved only partially by their prox./dist. half or epiphyses or the phal. bodies. Over $1 / 4$ of the finds $(26 \%)$ belonged to small Perdicinae species (Table 1). Similar was the share of the corvids, representing $34 \%$ of the material. The Alpine chough was the most abundant species in both localities, representing $25.6 \%$ and $29.5 \%$, respectively in the LP and EEH localities. Such a representation suggested a natural non-human accumulation of the material, probably indicating a former feeding place of a large raptor (eagle owl) in the cave. The collected material corresponded to the taphonomic conclusions of Bochenski (2005). Some bones (LAC B37 from LAC Ia) demonstrated features of digestion: their bone surface was not smooth and it was covered by a number of tiny pores. Both finds belonged to Perdix perdix from the EEH. On the other hand, the dominance of large to medium-sized preys (grey partridge, rock partridge, rock pigeon, common wood pigeon, yellow-billed Alpine chough), reaching $56.5 \%$ of the finds, explained the accumulation of the faunal remains by a large raptor, most probably eagle owl (Andrews, 1990), which was also represented in the collected bone material in the EEH cave locality. A detailed research on the metric characteristics of the recent eagle owl's preys in the region (Balkans; S Bulgaria), has found that the common bird preys of $B$. bubo are bird species with body mass between 100 and 500 grams (Boev, 1993). Namely, the five species listed above fall within this metric range.

Although suggesting the same taphonomy, the comparison of both avifaunas of the Loutra Almopias Cave showed that the LP avian locality was over five times poorer and provided 2.2 finds/taxa as compared to 10.8 finds/taxa from the EEH locality.
The anatomical representation of the avian skeletal elements was a rather unusual specific feature of both avian localities in the Loutra Almopias Cave. Over $68.4 \%$ ( 377 of the total of 551 finds) were phalanges and only three of them were wing phalanges. Another interesting feature was that $99.0 \%$ of the finds belonged to adult individuals and only six finds could be aged as pullets, juveniles or sub-adults.

\section{Paleoenvironment}

Both upper and uppermost Pleistocene sites of the Loutra Almopias Cave revealed an extremely varied avian fauna $[47$ species (68 taxa) represented by 551 bone finds, i.e. average of 8.1 finds per taxon]. It represented a wide variety of habitats in the surroundings, indicating the presence of a mosaic landscape.

Late Pleistocene (groundfloor chambers LAC I, II, III, Ib, Ic): LP record (19 taxa; 41 finds) belonged to at least six types of habitats: tundra and forest-steppes ( $L$. lagopus), conifer forests (B. bonasia, L. curvirostra), mixed or broadleaf forests (C. palumbus, Turdus sp., $C$. coccothraustes, $P$. pyrrhula), open steppe grasslands ( $P$. perdix, Melanocorhypha calandra), rocky hills/mountain habitats ( $F$. peregrinus, A. graeca, $C$. livia, B. bubo, P. graculus), openlands with scattered trees and shrubs (Anthus sp., P. pica). The complete absence of aquatic birds might be a result of the appearance of thermal springs in the area that influenced the hydrobionts, essential prey and food resource for many hydrophylous birds. Such thermal springs exist at present, but they could change their temperatures and appear and disappear during the millennia. The eagle owl (present in the fossil material) was the most probable accumulator of the faunal remains, which was suggested by the record of medium to large-sized birds, such as buzzards and black grouse, the high fragmentation of bones and lacking of skulls and the rare mandibles in the material (Bochenski et al., 1993).

Earliest Holocene (upper chamber LAC Ia): EEH record (48 species/genera; 510 finds). The uncovered fauna included elements of the "boreal complex" (7 species), inhabiting mainly coniferous forests (T. tetrix, B. bonasia, B. garrulus, L. curvirostra), forest-steppes (T. tetrix, L. lagopus) and/or tundra-type open/semiopenlands (B. lagopus, P. nivalis). The species of the wooded (mainly deciduous) mountains formed the largest group (17 species/taxa): C. palumbus, $D$. martius, O. scops, Caprimulgus sp., L. arborea, P. major, T. vuscivorus, S. vulgaris, F. coelebs, S. borin, $P$. ochruros, Erithacus/ Luscinia, S. europaea, $C$. coccothraustes, $P$. pyrrhula and $G$. glandarius. Particular attention must be paid to $C$. cinclus, 
represented by a relatively large number of finds (11 finds; $2.2 \%$ of the LAC assemblage). The whitethroated dipper is an indicator of the fast-running waters, i.e., rocky mountain streams and small rivers in the wooded mountains (Harrison, 1982). The petrophylous birds, inhabiting rock massifs in the mountain and rarely in lowlands, included eight species/ taxa: $F$. peregrinus, A. graeca, B. bubo, C. livia, Hirundo sp., $P$. graculus and $P$. pyrrhocorax, Riparia/Ptyonoprogne. The complex of the open country, open areas with scattered trees and openfoliaged broadleaved forests was represented by seven species: $F$. tinnunculus, $F$. vespertinus, $A$. noctua, Anthus sp., C. carduelis, $C$. chloris and $P$. pica. The grassy open hillsides, grasslands, grass moors and heathlands were inhabited by seven species/taxa - $P$. perdix, Alauda sp., G. cristata, Melanocorhypha calandra, Emberiza calandra and E. cirlus. Francolinus francolinus could also be referred to this group but this species usually prefers moister areas, shrubby thickets bordering water bodies and areas of scrubby herbage. Such a wide range of habitats may be explained by a mosaic-type distribution in the very end of the Pleistocene. It is well known from other LP localities in Europe and the continental parts of the Balkans (Bulgaria - Kozarnika Cave, Boev, 2001a, Cherdzhenitsa Cave, Boev, 2000a, Razhishka Cave, Boev, 2000b; and many others).

F. francolinus, B. lagopus, T. tetrix, L. lagopus and $P$. nivalis have disappeared from the recent bird fauna of Greece. The last four species have Arctic-Alpine ("boreal"), i.e., Arctic/Subarctic distribution and are presently found in high mountains during the summer, while the black francolin gradually reduced its breeding/resident range and disappeared from Europe (Harrison, 1982; Hagemeijer \& Blair, 1997).

The occurrence of Lagopus, a typical representative of the modern Arctic/Boreal fauna (and partly of $T$. tetrix), is among the southernmost Pleistocene records for this genus. This record (in both localities, LP and EEH) likely suggests that the genus Lagopus (as noticed by Bochenski, 2007) did not use to be strictly associated with a cold climate as it is today. It must be noted, that overall the origin of all the members of the family Tetraonidae (including genera Tetrao and Lagopus) was not associated with the cold climate (Boev, 1999; 2002).

Present-day climatic (temperature) preferences of some species ( $T$. tetrix, B. bonasia, $F$. francolinus, found in both cave localities, LP and EEH) indicate that the July isotherm (Harrison, 1982) of 21-26 ${ }^{\circ} \mathrm{C}$ encompassed the region of the cave and the climate probably used to be similar but slightly colder than the present one.
Faunal comparison of both avian localities in the Loutra Almopias Cave showed another clear difference: a number of species/taxa, inhabiting mainly woodland habitats, established in the EEH locality were completely absent in the older LP locality. These 15 (17) species/taxa were: L. arborea, B. garrulus, $S$. borin, S. europaea, T. viscivorus, Erithacus/Luscinia, G. glandarius, F. coelebs, C. chloris, S. vulgaris, $P$. major, D. martius, A. noctua, O. scops and Caprimulgus sp. Such a difference could be explained probably with the comparatively more humid (and relatively moderate) climate, allowing wide landscape forestation of the region surrounding the cave during the EEH. The large wooded areas probably used to be dominated by various broad-leaved species of trees (at least the distribution of the Eurasian jay follows the oak forests). In addition, the numerous records of the whitethroated dipper indicated the presence of running nonfreezing waters (woodland streams and small rivers) in the mountains. C. cinclus and Ph. ochruros are more closely related to rocky riverine habitats; nevertheless often they lie within the woodland ones.

In both localities the great majority of species represented in the fossil material belonged to the modern recent Balkan avifauna. The great majority of them were represented by their present-day breeding populations: $85.7 \%$ of species/taxa for the LP and $92.6 \%$ for the EEH.

It is interesting to note, that more of the boreal species have been found in the EEH locality. The paleoenvironment probably used to be more open than today and the mosaic woodland-open grassland landscape dominated. Forty-seven of the recorded species/taxa (69.1\%) from the Pleistocene deposits of the Loutra Almopias Cave are still spread in the region of the cave in the Voras Mts. (Table 1; Hagemeijer \& Blair, 1997). Among the disappeared species, the "boreal" and open-land steppe birds prevailed, indicating once again the drier and cooler former climate in the region in comparison to the local modern climate.

It is notable, that the fossil record of the Loutra Almopias Cave documented the continuous distribution of only eight species (11.8\%) - Falco sp. cf. F. peregrinus, A. graeca, C. palumbus, B. bubo, Anthus sp., $P$. graculus, $C$. coccothraustes and $P$. pyrrhula, that have been spread both in the LP and EEH and at present in the vicinity of the cave. On the other hand, ten species/genera (14.7\%) - Falco sp. cf. F. peregrinus, $A$. graeca, cf. B. bonasia, C. palumbus, B. bubo, Anthus sp., Turdus sp., P. graculus, C. coccothraustes, $P$. pyrrhula, have survived since the LP to the present in the region of the cave and $30(44.1 \%)$ of the species that inhabit the cave vicinity at present, used to existen- 
ce in the region even in the EEH, but were not recorded in the LP layers (see Table 1). Most of them are typical woodland birds, e.g. cf. Dryocopus martius, Lulula arborea, Bombicylla garrulus, Turdus sp. cf. T. vuscivorus, Erithacus/ Luscinia, Parus major, Sitta cf. europaea, Garrulus glandarius and Fringilla sp. cf. F. coelebs. One of them (Cinclus cinclus) is also a specific aquatic inhabitant.

\section{Concluding Remarks}

The fossil avian record of the Loutra Almopias Cave, from both sites in the cave of different age, corresponds to $15.4 \%$ of the recent avifauna of Greece, numbering 443 species (Lepage, 2017). In general, the fossil material proved that during the Late Pleistocene Earliest Holocene at least $73.3 \%$ (33 species/taxa) of the total of 45 species/taxa at present used to be represented by their resident populations, seven are summer migrants and four are winter migrants.

Six species of the uncovered fauna disappeared in the Holocene from the modern avifauna of Greece: $B$. lagopus, $F$. francolinus, $T$. tetrix, $L$. lagopus, $F$. vespertinus, and $P$. nivalis. The present breeding range of $B$. lagopus and $P$. nivalis is retreating northwards. Only one species ( $F r$. francolinus) disappeared from the modern bird fauna of Europe.

The range of $F$. francolinus retreated southeastwards in the Late Holocene, whereas T. tetrix and $F$. vespertinus still are breeding species in the neighbouring Bulgaria (Hagemeijer \& Blair 1997). Sometimes B. lagopus, B. garrulus and even P. nivalis make irregular irruptive migration to the Balkan region in the coldest winter periods (Cramp \& Simmons, 1980; Cramp \& Perrins 1994).

The fossil avifauna of the cave is an excellent example of the so-called "mixed" faunas of the Pleistocene. The coexistence of T. tetrix, L. lagopus and/or B. bonasia and A. graeca, P. perdix, P. graculus, Melanocorhypha spp. have been well documented throughout most of Europe (Poland, Tomek \& Bochenski, 2005; Spain, Bochenski, 2007; France, Italy, Sánchez Marco, 2004), including the Balkans - Bulgaria (Bochenski, 1982; Boev, 2001a) and Montenegro (Gál et al., 2003).

\section{Acknowledgements}

The first author (ZB) thanks Dr. Gerald Mayr (SFINM) for the provided skeleton of Fr. francolinus (7632), the editor Dr. Daniela Kalthoff (Department of Paleozoology, Swedish Museum of Natural History) and the reviewers of the manuscript, Dr. Zbigniew M. Bochenski (Institute of Systematics and Evolution of Animals in Krakow, Poland), Dr. John Stewart
(Bournemouth University in Bournemouth, United Kingdom), Dr. Dimitrios Michailidis (National and Kapodistrian University of Athens, Athens, Greece), Dr. Evangelos Vlachos (CONICET-Museo Paleontológico Egidio Feruglio, Argentina) and Dr. Petar Shurulinkov (NMNHS-BAS) for their reviews and very useful comments and remarks. Thanks to Mr. Assen Ignatov (NMNHS) for the photographs and Prof. Nikolay Spassov (NMNHS) for the provided literature and remarks to manuscript.

\section{References}

Andrews P. 1990 Owls, Caves and Fossils. Predation, preservation and accumulation of small mammal bones in caves, with an analysis of the Pleistocene cave faunas from Westbury-subMendip, Somerset, UK. Natural History Museum Publications. London, $231 \mathrm{pp}$.

Anonym., 2018. https://natureguide.gr/desc/Birds/Snow_Bunting/

Babayev I., van den Berk V., Potapov R. 1997 Francolunus francolinus Black Francolin. In: Hagemeijer W. J. M., Blair M. J. (eds.) The EBCC Atlas of European Breeding Birds. Their Distribution and Abundance. T. \& A. D. Poyser, London, 211.

Baumel J., Witmer L. 1993 Osteologia. In: Baumel J., King A., Breazile J., Evans H., Vanden Berge J. (eds.) In: Handbook of Avian Anatomy, Nomina Anatomica Avium. Nutall Ornithological Club 23: 45-132.

Bochenski Z. 1982 Aves. In: Kozlowski J. (ed.) Excavation in the Bacho Kiro Cave (Bulgaria). Final Report, Panstwowe Wydawnictwo Naukowe, Warszawa, 31-38.

Bochenski Z. M. 2005 Owls, diurnal raptors and humans: signatures on avian bones. In: O' Connor T. (ed.) 9th ICAZ Conference, Durham 2002 "Biosphere to Lithosphere". Oxbow Books, Oxford, 31-45.

Bochenski Z. 2007 The Middle Pleistocene avifauna from Pinilla del Valle (Spain). Geobios 40: 31-37.

Bochenski Z. M., Tomek T. 2010 The birds of Klissoura Cave 1: a window into the Upper Palaeolithic Greece. Eurasian Prehistory 7 (2): 91-106.

Bochenski Z. M., Tomek T., Boev Z., Mitev I. 1993 Patterns of bird bone fragmentation in pellets of the Tawny Owl (Strix aluco) and the Eagle Owl (Bubo bubo) and their taphonomic implications. Acta zoologica cracoviensia 36 (2): 313-328.

Bochenski Z. M., Tomek T., Wertz K., Kaczanowska M., Kozłowski J., Sampson A. 2018 Who ate the birds: the taphonomy of Sarakenos Cave, Greece. Archaeological and Anthropological Sciences 10: 1603-1615. 
Boev Z. 1993 Species composition and metrical characterization of the birds - victims of the Eagle owl (Bubo bubo (L., 1758)) (Aves, Strigidae). Historia naturalis bulgarica 4: 47-56. (In Bulgarian)

Boev Z. 1999 Neogenski i kvaternerni ptitsi (Aves) ot Balgariya. [Neogene and Quaternary birds (Aves) from Bulgaria]. Bulgarian Acadademy of Sciences, National Museum of Natural History D. Sci. Thesis, Sofia, 243 pp. (In Bulgarian)

Boev Z. 2000a Early Pleistocene and Early Holocene avifauna of the Cherdzhenitsa Cave, Northwestern Bulgaria. Historia naturalis bulgarica 11: 107-116.

Boev Z. 2000b Late Pleistocene Avifauna of the Razhishkata Cave, Western Bulgaria. Historia naturalis bulgarica 12: 71-87.

Boev Z. 2001a Late Pleistocene birds from the Kozarnika Cave (Montana District; NW Bulgaria). In: Delchev P., Shanov S., Benderev A. (eds.) Karst. Vol. I. Proceedings of the First National Conference on Environment and Cultural Heritage in Karst. Sofia, 10.-11.11.2000. Earth and Man National Museum, Association of Environment and Cultural Heritage in Karst, Sofia, 113-128.

Boev Z. 2001b Birds over the mammoth's head in Bulgaria. In: Cavaretta G., Gioia P., Mussi M., Palombo M. (eds.) The World of Elephants. Proceedings of the 1st International Congress, 16-20.10.2001. Consiglio Nazionale delle Ricerche, Rome, 180-186.

Boev Z. 2002 Tetraonidae Vigors, 1825 (Galliformes Aves) in the Neogene-Quaternary record of Bulgaria and the origin and evolution of the family. In: Bochenski Z. M., Bochenski Z., Stewart J. (eds.) Proceedings of the 4th Meeting of the ICAZ Bird Working Group, Krakow, Poland, 11-15.09.2001. Acta zoologica cracoviensia 45: 263-282.

Bogoćević K., Dimitriević V. 2004 Quaternary fauna from Mališina Stijena near Pljevlja (Montenegro). Zbornik radova Odbora za kras i speleologiju, SANJ 8: 119-133.

Cramp S., Perrins C. 1994 Handbook of the Birds of Europe, the Middle East and North Africa. The Birds of Western Palearctic, Vol. IX. Bunting and New World Warblers. Oxford University Press, Oxford New York 488 pp.

Cramp S., Simmons K. 1980 Handbook of the Birds of Europe the Middle East and North Africa. The Birds of Western Palearctic, Vol. II. Hawks to Bustards. Oxford University Press, Oxford London New York 695 pp.

del Hoyo J., Collar N. 2014 HBW and BirdLife International Illustrated Checklist of the Birds of the World. Volume 1. Non-passerines. Lynx Edicions, Barcelona, 903 pp.

del Hoyo J., Collar N. 2016 HBW and BirdLife International Illustrated Checklist of the Birds of the World. Volume 2. Passerines. Lynx Edicions, Barcelona, 1013 pp.

dos Anjos L. 2009 Corvidae (Crows). In: del Hoyo J., Elliot A., Christie D.A. (eds.) Handbook of the Birds of ther World. Vol. 14. Bush-shrikes to Old World Sparrows. Lynx Edicions, Barcelona, 494640.

Gál E., Dimitrijevic V., Kessler E. 2003 Bird remains from the Late Pleistocene deposits of Mališhina Stijena (Montenegro). Theoretical and Applied Karstology 16: 67-75.

Hagemeijer W., Blair M. 1997 The EBCC Atlas of European Breeding Birds. Their Distribution and Abundance. T. \& A. D. Poyser, London, 903 pp.

Harrison C. 1982 An atlas of the Birds of the Western Palaearctic. Princeton University Press, New Jersey, $322 \mathrm{pp}$.

Janossy D. 1972 Die Mittelpleistozäne Vogelfauna der Stranska Skala (1910-1945). In: Musil R. (ed.): Stranska Skala 1910-1945. Anthropos, Brno 20 (12): 35-64.

Kraft E. 1972 Vergleichend Morphologische Untersuchungen an Einzelknochen Nord- und Mitteleropäischer Kleinerer Hühnervögel. Inaugural-Dissertation Munchen, $192 \mathrm{pp}$.

Lepage D. 2017 Avibase - Bird Checklists of the World. Greece. https://avibase.bsc-eoc.org/checklist.jsp? region $=$ GR (06.06.2017).

Livezey B., Zusi R. 2006 Higher order phylogeny of modern birds (Theropoda, Aves: Neornithes) based on comparative anatomy: I. Methods and characters. Bulletin of Carnegie Museum of Natural History 37: 1-556.

Mlíkovský J. 1995 Middle Pleistocene birds of Elaiochoria 3, Greece. In: Peters D. (ed.) Acta palaeornithologica. 3. Symposium SAPE. 5. International Senckenberg-Konferenz 22-26 Juni 1992. Courier Forschungsinstitut Senckenberg 181: 271-273.

Mlíkovský J. 2002 Cenozoic Birds of the World. Part 1: Europe. Ninox Press, Praha, 406 pp.

Mlíkovský J. 2007 Middle Pleistocene birds from Petralona K-23, Greece. Acta Societatis Zoologicae Bohemicae 71: 193-195.

Mourer-Chauviré C. 1993 The Pleistocene avifaunas of Europe. Archaeofauna 2: 53-66.

Rabeder G. Tsoukala E., Kavcik N. 2006 Chronological and systematic position of cave bears from Loutrá Almopias (Macedonia, Greece). In: Tsoukala E., Rabeder, G. (eds.) Proceedings of the 12th International Cave Bear Symposium, Thessaloniki/Aridea, 2-5 
November 2006. Scientific Annals, School of Geology, Aristotle University 98: 69-73.

Sánchez Marco A. 2004 Avian zoogeographical patterns during the Quaternary in the Mediterranean region and paleoclimatic interpretation. Ardeola 51 (1): 91-132.

Tomek T. Bochenski Z.M. 2000 The Comparative Osteology of European Corvids (Aves: Corvidae), with a key to the identification of their skeletal elements. Instytut Systematyki i Ewolucji Zwierząt, Polska Akademia Nauk, Krakow, 102 pp.

Tomek T. Bochenski Z. 2005 Weichselian and Holocene bird remains from Komarowa Cave, Central Poland. Acta zoologica cracoviensia 48 (1-2): 4365.

Tsoukala E., Chatzopoulou K., Rabeder G., Pappa S., Nagel D. Withalm G. 2006 Paleontological and stratigraphical research in Loutra Almopias bear cave (Almopia Speleopark, Pella, Macedonia, Greece). Scientific Annals, School of Geology, Aristotle University, Athenes, Special volume 98: 41-67.

Tyrberg T. 1991 Arctic, Montane and Steppe birds as Glacial relicts in the West Palearctic. Ornithologische Verhandlungen 25: 29-49.

Tyrberg T. 1998 Pleistocene Birds of the Palearctic: a Catalogue. Publications of the Nuttall Ornithological Club, 27, Published by the Club, Cambridge Massachusetts, $720 \mathrm{pp}$.

Tyrberg T. 2008 Supplement to "Pleistocene birds of the Palearctic". http://web.telia.com/ u11502098/ pleistocene.pdf.

Walker M, Johnsen, S., Rasmussen, S., Popp, T., Steffensen, J.-P., Gibbard, P., Hoek, W., Lowe, J., Andrews, J., Bjorck, S., Cwynar, L., Hughen, K., Kershaw, P., Kromer, B., Litt, T., Lowe, D., Nakagawa, T., Newnham, R., Schwander, J. 2009. Formal definition and dating of the GSSP (Global Stratotype Section and Point) for the base of the Holocene using the Greenland NGRIP ice core, and selected auxiliary records. Journal of Quaternary Science 24(1): 3-17

Wilczyński J. Tomek, T., Nadachowski A., MiękinaB., Rzebik-Kowalska B., Pereswiet-Soltan A., Stworzewicz E., Szyndlar Z., Marciszak A., Lõugas L. 2016 Faunal record and environmental changes during Holocene and Pleistocene. In: Kaczanowska M., Kozłowski J., Sampson A. (eds.) The Sarakenos Cave at Akraephnion, Boeotia, Greece. Vol. II. The Early Neolithic, the Mesolithic and the Final Palaeolithic (Excavations in Trench A). The Polish Academy of Arts and Sciences Kraków, 63-80.

\section{Appendix 1}

List of Late Pleistocene (LP) and Earliest Holocene (EEH) avian specimens per taxon from the Loutra Almopias Cave. All specimens are part of the LGPUT LAC B collection. See main text for abbreviations.

Perdix perdix: EEH: B156, coracoid sin. dist.; B185, furcula (symphysis clavicularis); B296, ph. dist. d. II p. sin.; B344, coracoid dex. dist. (acrocoracoidal part); B387, ph. dist. d. III p. sin. (dist. end damaged); B391, ph. dist. d. IV p. dex.; B427, ph. dist. d. III p. sin. (dist. end damaged); B441, ph. 3 d. IV p. sin.; B462, ph. 3 d. IV p. sin.; B525, ph. dist. d. IV p. sin. (dist. end damaged); B549, ph. dist. d. IV p. dex.; cf. Perdix perdix: LP: B22, ph. 1 d. II p. dex. dist. (prox. end damaged); B42, ph. 1 d. I p. dex.; EEH: B1, ph. 1 d. II p. sin. dist. (prox. end damaged); B9, ph. 1 d. I p. dex. (f. a. prox. partly damaged); B10, ph. 1 d. III p. sin. (prox. end damaged); B16, ph. 1 d. I p. sin. dist. (prox. end damaged); B26, ph. 1 d. III p. dex. ad.; B28, ph. 3 d. IV p. sin. dist. (prox. end damaged); B29, ph. 3 d. III p. dex.; B37, ph. 1 d. I p. sin. (digested); B47, ph. 1 d. I p. dex.; B51, ph. 1 d. III p. sin. dist. (prox. end damaged); B66, ph. 1 d. I p. dex. dist. (prox. end damaged); B69, ph. 1 d. I p. sin. (dist. end damaged); B78, ph. 2 d. II p. dex.; B79, ph. 2 d. III p. dex. dist. (prox. end damaged); B80, ph. 1 d. I p. dex.; B81, ph. 4 d. IV p. sin.; B84, ph. 1 d. III p. dex. dist.; B144, tmt sin. prox. (splinter); B154, coracoid sin. prox.; B178, cmc dex. prox. juv. (partly damaged); B182, ulna dex. prox.; B183, cmc dex. prox.; B189, ulna sin. prox. (splinter); B197, cmc dex. prox. (damaged); B206, furcula (symphysis clavicularis); B211, ph. $1 \mathrm{~d}$. III p. sin. prox.; B218, ph. 1 d. III p. sin. prox.; B219, radius sin. prox.; B220, tmt dex. dist. (tr. mt. IV); B241, ph. dist. d. IV p. dex.; B247, ph. 2 d. IV p. sin. (split); B351, ph. dist. d. IV p. dex.; B354, ph. dist. d. II p. sin. (dist. end damaged); B392, ph. dist. d. IV p. dex. (dist. end damaged); B475, ph. dist. d. IV p. sin.; B484, ph. 4 d. IV p. prox. dex. (dist. end damaged); B501, ph. dist. d. IV p. sin.; B535, ph. dist. d. II p. sin. (dist. end damaged); B537, ph. dist. d. I p. dex.; B538, ph. dist. d. IV p. $\sin$.

Perdix sp.: EEH: B174, ph. 2 d. III p. dex. $(\#<$ Alectoris, P. perdix); B70, ph. 4 d. IV p. sin. dist. (dorsal surface damaged); (cf.): EEH: B45, ph. 2 d. III p. sin. (phal. body split; LP: B157, ulna sin. $\left(2^{\text {nd }}\right.$ third of diaphysis); B291, ph. 2 d. IV p. dex. (damaged).

Alectoris graeca: EEH: B 40, ph. 1 d. I p. sin.; B138, radius sin. prox.; B263, ph. dist. d. III p. dex.; B451, ph. dist. d. IV p. sin.; B513, ph. dist. d. III p. sin.; cf. Alectoris graeca: LP: B192, tmt sin. dist. 
(tr. mt. IV); EEH: B5, ph. 1 d. IV p. sin.; B12, ph. 2 d. IV p. dex.; B14, ph. 1 d. IV p. dex.; B15, ph. 1 d. III p. sin. prox. (dist. end damaged); B21, ph. 1 d. II p. dex. (f. a. prox. damaged); B23, ph. 1 d. III p. sin. dist. (prox. end damaged); B31, ph. 2 d. IV p. sin. (<A. graeca); B35, ph. 1 d. IV p. dex.; B36, ph. 2 d. III p. sin. prox.; B49, radius sin. prox.; B53, ph. 2 d. III p. sin.; B54, ph. 1 d. III p. sin. prox. (dist. end damaged); B75, ph. 4 d. IV p. sin. (f. a. dist. partly damaged); B77, ph. 1 d. III p. sin. dist. (prox. half missing); B83, ph. 3 d. IV p. sin.; B111, ph. dist. d. I p. dex.; B172, tbt sin. dist.; B105, ph. dist. d. IV p. sin. (dist. end damaged); B142, furcula (symphysis clavicularis); B164, hum. dex. prox.; 216 radius dex. dist.; B235, ph. dist. d. III p. sin. (dist. end damaged); B283, ph. 2 d. IV p. sin. (thinner phal. body); B294, ph. 4 d. IV p. sin.; B305, ph. dist. d. IV p. dex. (f. a. narrower than in $A$. graeca); B357, ph. dist. d. I p. dex.; B360, ph. dist. d. I p. dex.; B364, ph. dist. d. I p. sin.; B389, ph. dist. d. I p. dex. (dist. end damaged); B410, ph. dist. d. IV p. sin. (dist. end damaged); B460, ph. 2 d. IV p. sin. (thinner phal. body); B463, ph. dist. d. III p. dex.; B464, ph. 2 d. IV p. sin.; B465, ph. dist. d. II p. sin. (dist. end damaged); B466, ph. dist. d. II p. dex.; B479, ph. 2 d. IV p. sin. (thinner phal. body); B518, ph. dist. d. III p. dex. (dist. end damaged); B524, ph. dist. d. II p. sin.; B526, ph. 2 d. IV p. sin. (dist. end damaged); B542, ph. dist. d. IV p. dex.

Alectoris sp.: LP: B141 coracoid sin. dist.; B417, ph. dist. d. III p. sin. (f. a. narrower than in $A$. graeca); EEH: B27, ph. 2 d. III p. sin. dist. (prox. end damaged); B148, ph. 2 d. III p. sin. (f. a. prox. partly damaged); B386, ph. dist. d. I p. dex.; B399, ph. dist. d. I p. sin.; B420, ph. dist. d. II p. dex. (dist. end damaged); cf. Alectoris sp.: LP: B414, ph. dist. d. III p. sin. (f. a. narrower than in $A$. graeca); EEH: B7, ph. 4 d. IV p. sin.; B41, ph. 1 d. IV p. dex. (prox. end broken); B46, ph. 3 d. III p. dex. dist. (f. a. prox. partly damaged); B56, ph. 4 d. IV p. sin.; B59, ph. 2 d. III p. sin.; B62, ph. 2 d. II p. sin. (f. a. prox. partly damaged; B65, ph. 1 d. III p. dex.; B86, ph. dist. d. III p. sin.; B102, ph. 4 d. III p. sin. (dist. end damaged); B118, ph. dist. d. III p. sin. prox. (prox. end damaged); B230, ph. dist. d. I p. sin.; B242, ph. dist. d. I p. sin. (prox. end damaged); B279, ph. dist. d. IV p. dex.; B457, ph. dist. d. II p. sin. (f. a. narrower than in A. graeca).

Francolinus francolinus: LP: B150, coracoid sin. prox.; EEH: B163, sternum, pars coracoidalis.

Francolinus sp.: EEH: B372, tmt dex. tr. m. IV.

Alectoris/ Francolinus: EEH: B260, ph. 3 d. IV p. dex.; B435, ph. 2 d. IV p. dex.
Perdix/ Francolinus: EEH: B531, ph. 3 dist. d. III p. dex.; B532, ph. 3 d. III p. sin. (thinner than Perdix): B497, ph. 4 d. IV p. sin.; B316, ph. 4 d. IV p. sin. (< Perdix); B298, ph. 2 d. IV p. sin. (shorter and thicker than $P$. perdix).

Perdicinae gen. indet.: EEH: B30, ph. 1 d. IV p. dex. (\#< Perdix, Fr. francolinus, $>$ thicker C. coturtnix; B32, ph. 1 d. I p. dex. (f. a. damaged; \# Alectoris, Perdix, Coturnix); B33, ph. 1 d. III p. sin. (\# Alectoris, Perdix, Coturnix; longer and thinner than $F$. francolinus); B34, ph. 1 d. I p. dex. (f. a. partly damaged; <Alectoris, Perdix, Fr. francolinus, $<$ C. coturnix); B136, ph. 2 d. IV p. sin. (cf. Alectoris; B151, ph. 2 d. III p. dex. prox. (\#<Alectoris, Perdix, \#); B214, ph. 2 d. II p. dex. prox. (cf. Alectoris).

Tetrao tetrix: EEH: B67, ph. 1 d. III p. sin. (f. a. prox. partly damaged); B139, ulnare sin.

Lagopus cf. lagopus: LP: B165, hum. dex. dist.; B486, ph. dist d. I p. dex.; EEH: B166, furcula (symphysis clavicularis).

aff. Lagopus sp.: EEH: B68, ph. 1 d. III p. sin. prox.

cf. Bonasa bonasia: LP: B177, tmt dex. dist. (tr. mt. IV).

Bonasa bonasia/ Lagopus muta: EEH: B350, ph. dist. d. I p. dex.; B395, ph. dist. d. II p. sin.; B409, ph. dist. d. IV p. dex.

Columba livia: LP: B III: B400, ph. dist. d. III p. dex. (prox. end damaged); EEH: B140, femur sin. dist.; B222, ph. dist. d. IV p. sin. (prox. end damaged); B237, ph. dist. d. IV p. sin.; B248, ph. dist. d. III p. sin. (dist. end damaged); B251, ph. dist. d. IV p. prox. dex. (prox. end damaged); B252, ph. dist. d. IV p. sin.; B256, ph. dist. d. II p. dex.; B268, ph. dist. d. III p. sin. (dist. end damaged); B308, ph. dist. d. I p. dex.; B384, ph. dist. d. IV p. sin. (prox. end damaged); B388, ph. dist. d. III p. sin. (dist. end damaged); B404, ph. dist. d. IV p. dex.; B405, ph. dist. d. II p. dex. (dist. end damaged); B416, furcula (symphysal part); B433, ph. dist. d. III p. prox. dex. (dist. end damaged); B448, ph. 3 d. IV p. sin.; B450, furcula (symphysal part); B455, ph. dist. d. III p. sin.; B495, ph. dist. d. IV p. dex.; B500, ph. dist. d. IV p. sin. (dist. end damaged); B551, ph. dist. d. III p. dex. (prox. end damaged); B400 ph. dist. d. III p. dex. (prox. end damaged); cf. Columba livia: EEH: B162, hum. dex. prox. (caput humeri).

Columba palumbus: LP: B415, furcula (symphysal part); EEH: B231, ph. dist. d. IV p. sin.; B421, furcula (symphysal part); cf. Columba palumbus: LP: B124, ph. d. IV p. sin.; EEH: B169, furcula (symphysis clavicularis); B210, furcula (symphysis clavicularis); B229, ph. 2 d. IV p. dex.; B270, ph. 
dist. d. I p. dex.; B271, ph. dist. d. I p. dex.; B297, ph. dist. d. IV sin. (dist. end damaged); $311 \mathrm{ph}$. dist. d. IV p. dex. (dist. end damaged); B359, ph. dist. d. I p. dex. (dist. end damaged); B366 ph. dist. d. III p. sin. (prox. end damaged).

? Caprimulgus sp.: EEH: B331, tmt dex. dist. pull. / juv.

Buteo sp. cf. B. lagopus: EEH: B63, ph. dist. d. IV p. dex. ?sad.

Falco sp. cf. F. peregrinus: LP: B126, ph. dist. d. II p. dex. (f. a. damaged and missing), dist. end broken; B93, ph. dist. d. IV p. sin. (dist. end damaged); B146, ph. dist. d. IV p. (dist. end damaged).

Falco sp. ex gr. . . cherrug: EEH: B153, ph. dist. d. III p. dex. prox. (dist. end and dorsal part of f. a. are damaged).

Falco sp. cf. tinnunculus: EEH: B 24, ph. dist. d. II p. dex. prox. (dist. end damaged); B39, ph. dist. d. IV p. sin. (dist. end damaged); B71, ph. 1 d. III p. sin.; B72, ph. 1 d. III p. sin.; B238, ph. dist. d. I p. sin.; B272, ph. dist. d. III p. sin.; B362, ph. dist. d. III p. prox. sin. (dist. end damaged); B 382, ph. dist. d. IV p. prox. sin. (dist. end damaged); B396, ph. dist. d. IV p. dex.; B438, ph. dist. d. II p. sin.; B 477, ph. dist. d. IV p. dex.; B487, ph. dist. d. IV p. sin. (dist. end damaged); B498, ph. dist. d. IV p. (prox. dex. dist. end damaged).

Falco sp. cf. vespertinus: EEH: B379, ph. dist. d. IV p. dex.; B461, ph. dist. d. III p. prox. dex. (dist. end damaged); B474, ph. dist. d. IV p. dex. (dist. end damaged); B507, ph. dist. d. III p. dex.; B 510 ph. 2 d. III p. sin.

Falco sp. ex gr. tinnunculus: EEH: B439, ph. 2 d. III p. $\sin$.

Bubo bubo: LP: B419, tmt dex.; B167, ph. 2 d. III p. dex.; B168, ph. 1 d. III p. dex.; EEH: B343, ph. 3 d. III p. sin.; B137, ph. dist. d. I p. sin.; B143, ph. 3 d. III p. sin.; B147, ph. 2 d. III p. sin.; B152, ph. 1 d. III p. dex. prox.

Athene noctua: EEH: B38, ph. 2 d. III p. dex. dist. (f. a. damaged).

cf. Otus scops: EEH: B481, ph. dist. d. IV p. sin.

cf. Dryocopus martius: EEH: B123, ph. dist. d. IV p. $\sin$.

cf. Picidae: EEH: B483, ph. dist. d. p.

Galerida sp. cf. G. cristata: EEH: B213, hum. sin. prox.; B275, tmt sin. dist.; B312, tmt dex. dist. ? sad. (damaged); B458, tmt sin. dist. (tr. m. III and IV).

Melanocorhypha calandra: EEH: B287, tmt dex. dist. (damaged); B422, tmt sin. dist.; cf. Melanocorhypha calandra: LP: B186, tmt dex. dist.; EEH: B302, tmt dex. dist. (tr. m. III and IV).

Melanocorhypha sp.: EEH: B318, tmt dex. dist. (tr. m. III and IV); B381, ph. dist. d. I p. sin. (damaged in processing).
Alauda sp.: EEH: B132, hum. sin. dist. (\# Alauda arvensis); B133, hum. sin. dist. (\# Alauda arvensis).

Lulula arborea: EEH: B258, tmt sin. dist.; cf. Lulula arborea: EEH: B522, tmt dex. dist. (tr. mt. IV damaged); B523, tmt sin. dist. (tr. m. III and IV).

cf. Hirundo sp.: B478, ulna dex. dist. (<H. rustica).

Riparia/ Ptyonoprogne.: EEH: B333, tmt sin. dist.

Anthus sp.: EEH: B492, tmt sin. dist. (cf. A. trivialis); cf. Anthus sp.: LP: B181, ph. dist. d. I p. $(>A$. trivialis).

Bombicylla garrulus: EEH: B544, tmt sin. dist.

Cinclus cinclus: EEH: B397, ph. dist. d. I p. dex.; B239, ph. dist. d. III p. dex.; B426, ph. dist. d. III p. dex.; cf. Cinclus cinclus: EEH B246, ph. dist. d. II p. dex.; B393, tmt sin. dist. juv.; B394, ph. dist. d. IV p. dex. (prox. end damaged); B440, tmt dex. dist. (tr. m. IV damaged); B446, ph. dist. d. I p. sin.; B490, ph. dist. d. III p. dex.; B536, ph. dist. d. III p. sin.; B431, ph. dist. d. I p. sin.

Turdus sp. cf. T. viscivorus: EEH: B190, tmt dex. (tr. mt. II and III).

Turdus sp.: LP: B200, tmt dex. dist. (tr. mt. II and part of tr. mt. IV are damaged; \# T. philomelos size).

Sylvia sp. cf. S. borin: EEH: B329, tmt dex. dist. (tr. m. II and IV damaged).

Phoenicurus sp. cf. P. ochruros: EEH: B309, ulna sin. dist.

Erithacus/ Luscinia: EEH: B327, tmt sin. dist. (dist. end damaged).

Parus major: EEH: B303, hum. sin. prox.; B317, ulna sin. dist.; B321, tmt dex. dist.

Sitta cf. europaea: EEH: B355, ph. dist. d. III p. sin.

Sitta sp.: EEH: B324, tmt sin. dist.

Garrulus glandarius: EEH: B61, ph. 3 d. III p. dex.; B110, ph. dist. d. I p. sin.; B196, tmt sin. dist. (tr. mt. II and III).

Pica pica: LP: B198, tmt sin. dist. (tr. mt. III and IV); EEH: B195, tmt sin. dist.; (cf.): EEH: B19, ph. 1 d. IV p. sin. (prox. end partly damaged).

Pica sp.: B13, ph. prox. d. majoris dex.

Pyrrhocorax graculus: LP: B155, ulna sin. (diaphysal part /3rd fifth; splinter of the IV-V papilae remigales caudales); B109, ph. dist. d. IV p. dex.; (dist. end damaged); B120, ph. dist. d. III p. dex. (dist. end damaged); B125, ph. dist. d. II p. dex. (dist. end damaged); B127, ph. dist. d. I p. dex. (dist. end damaged); B128, ph. dist. d. IV p. dex.; B129, ph. dist. d. III p. dex. (dist. end damaged); B193, tmt dex. dist. (tr. mt. III and IV); EEH: B2, ph. 3 d. IV p. sin.; B4, ph. 1 d. I p. dex. dist. (prox. end damaged); B17, ph. 1 d. I p. dex. dist. (prox. end damaged); B20, tmt dex. dist. (tr. mt. II and III); B25, ph. 2 d. II p. dex.; B43, ph. 1 d. II p. dex. prox. (dist. end damaged); B44, ph. 2 d. II p. sin.; 
B50, ph. 4 d. IV p. sin.; B58, tmt sin. dist. (tr. mt. II and III); B76, ph. 1 d. IV p. sin.; B82, ph. 3 d. III p. sin.; B85, ph. dist. d. II p. sin. (dist. end damaged); B87, ph. dist. d. II p. sin. (dist. end damaged; B88, ph. dist. d. IV p. dex. (dist. end damaged); B89, ph. dist. d. III p. sin. (dist. end damaged); B90, ph. dist. d. I p. sin. prox. (dist. end damaged); B91, ph. dist. d. I p. sin. prox. (dist. end damaged); B92, ph. dist. d. III p. dex. prox. (dist. end damaged); B94, ph. dist. d. II p. dex. (dist. end damaged); B96, ph. dist. d. II p. dex. prox.; B97, ph. dist. d. III p. sin. (dist. end damaged); B98, ph. dist. d. I p. sin. (dist. end damaged); B99, ph. dist. d. IV p. sin. (dist. end damaged); B100, ph. dist. d. II p. dex.; B101, ph. dist. d. III p. sin. prox. (dist. end damaged); B103, ph. dist. d. II p. dex. (dist. end damaged); B104, ph. dist. d. III p. dex.; B106, ph. dist. d. IV p. sin. (dist. end and dosal surface damaged); B107, ph. dist. d. III p. sin. dist. (prox. half missing); B108, ph. dist. d. I p. sin.; B113, ph. dist. d. I p. dex.; B114, ph. dist. d. II p. dex. (dist. end damaged); B115, ph. dist. d. IV p. sin.; B116, ph. dist. d. I p. sin.; B119, ph. dist. d. I p. dex. (dist. end damaged); B121, ph. dist. d. II p. dex. (dist. end damaged); B122, ph. dist. d. II p. sin. (dist. end damaged); B130, ph. dist. d. II p. dex. (dist. end damaged); B145, tmt dex. dist.; 149 ulna sin. dist.; B170, femur dex. dist.; B171, mandibula pars symphysalis; B176, tmt sin. dist.; B179, tmt sin. dist.; B184, tmt dex. dist. (tr. mt. III and IV); B201, tmt sin. dist. (tr. mt. II and III); B205, tmt dex. (tr. mt. II and III); B208, ulna dex. dist.); B212, ph. 2 d. II p. sin.; B217, ph. dist. d. IV p. dex. (dist. end damaged); B225, ph. 2 d. II p. sin.; B226, ph. dist. d. III p. dex.; B227, ph. dist. d. II p. sin.; B228, ph. dist. d. III p. sin.; B232, ph. dist. d. III p. dex. (dist. end damaged); B234, ph. dist. d. IV dex.; B236, ph. dist. d. III p. dex. (dist. end damaged; B244, ph. dist. d. IV p. sin. (dist. end damaged); B245, ph. dist. d. IV p. dex.; B250, ph. dist. d. IV p. dex. (dist. end damaged); B253, ph. dist. d. IV p. sin.; B254, ph. dist. d. IV p. sin.; B259, ph. dist. d. II p. sin. (dist. end damaged); B261, ph. dist. d. III p. sin.; B264, tmt sin. dist. (tr. mt. III and IV); B265, ph. dist. d. I p. sin. (damaged); B269, ph. dist. d. I p. sin. (damaged); B274, ph. 2 d. IV p. dex.; B276, ph. dist. d. II p. sin. (dist. end damaged); B277, ph. dist. d. IV p. dex. (dist. end damaged); B278, ph. dist. d. III p. sin. (dist. end damaged; B282, ph. dist. d. IV p. dex. (dist. end damaged); B284, ph. dist. d. IV p. sin.; B285, ph. 2 d. II p. dex.; B286, ph. dist. d. II p. dex. (dist. end damaged); B290, ph. 3 d. III p. sin.; B293, ph. dist. d. IV p. dex.; B295, ph. dist. d. IV p. sin.; B299, radius sin. prox.; B304, ph. 2 d. IV p. dex.; B310, ph. dist. d.
IV p. sin.; B319, ph. dist. d. III p. sin. prox. (dist. end damaged); B345, coracoid sin. prox.; B349, ph. dist. d. III p. sin.; B353, ph. dist. d. IV p. sin.; B358, tmt dex. dist. (epiphysis); B361, ph. dist. d. II p. sin. (dist. and prox. ends damaged); B363, ph. dist. d. I p. dex. (prox. end damaged; B368, ph. dist. d. III p. sin. (prox. dist. end damaged); B369, ph. dist. d. IV p. sin. (dist. end damaged); B370, ph. dist. d. IV p. dex. (dist. end damaged); B371, ph. dist. d. IV p. sin.; B373, ph. dist. d. III p. sin. (dist. end damaged); B383, ph. dist. d. III p. sin. prox. (dist. end damaged); B425, ph. dist. d. III p. sin. (dist. end damaged); B434, ph. 1 d. II p. dex. (prox. end damaged); B447, ph. 2 d. III p. sin.; B449, tmt sin. dist. (tr. mt III and IV); B452, ph. dist. d. III p. sin. prox. (dist. end damaged); B453, ph. dist. d. IV sin.; B459, ph. dist. d. IV p. dex. (dist. end damaged); B469, ph. 4 d. IV p. sin. (dist. end damaged); B470, ph. dist. d. III p. sin. prox. (dist. end damaged); B472, ph. dist. d. IV p. sin. (dist. end damaged); B476, ph. dist. d. III p. dex. (dist. end damaged); B482, ph. dist. d. IV p. sin.; 485 radius sin. prox.; B488, ph. I d. IV p. dex.; B491, radius sin. prox.; B502, ph. dist. d. III p. sin. (dist. end damaged); B505, ph. 3 d. IV p. dex.; B508, ph. dist. d. IV p. sin.; B511, ph. 3 d. IV p. sin.; B516, ph. 2 d. IV p. dex.; B517, ph. dist. d. IV p. dex. (dist. end damaged); B527, ph. dist. d. III p. sin. (dist. end damaged); B529, ph. 4 d. IV p. dex.; B530, ph. 4 d. IV p. dex.; B539, ph. dist. d. III p. dex. (damaged); B540, ph. dist. d. III p. dex. (dist. end damaged); B543, ph. dist. d. III p. sin. (dist. end damaged); B545, ph. 2 d. IV p. sin.; B548, ph. dist. d. III p. sin. (damaged); cf. Pyrrhocorax graculus: LP: B418, ph. dist. d. IV p. sin. (dist. end damaged); B160, hum. dist. dex. (part of dist. epiphisys); B161, ulna sin. prox. (splinter with cotyla dorsalis); EEH: B18, ph. 3 d. IV p. sin. prox. (dist. end damaged); B52, ph. 1 d. II p. sin.); B57, ph. 2 d. III p. dex. (f. a. partly damaged); B60, ph. 2 d. III p. dex.; B64, ph. 4 d. IV p. sin.; B74, ph. 1 d. IV p. dex.; B95, ph. dist. d. II p. dex. (dist. end damaged); B112, ph. dist. d. II p. dex. (dist. end damaged); B215, ph. dist. d. II p. dex. prox. (dist. end damaged); B221, ph. dist. IV p. dex. prox. (dist. end damaged); B241, ph. dist. d. IV p. dex. prox.; B255, ph. dist. d. III p. sin. (dist. end damaged); B301, ph. dist. d. III p. sin. prox. (dist. end damaged; B306, ph. dist. d. III p. sin. prox. (dist. end damaged; B314, ph. dist. d. III p. dex. (prox. end damaged); B356, tmt sin. dist. (tr. mt. II and III); B428, ph. 2 d. III p. sin. ? juv.; B430, ph. 3 dist. d. IV p. dex.; B432, ph. dist. d. IV p. sin. (prox. end damaged); B442, ph. dist. d. III p. sin. (dist. end damaged); B468, ph. dist. d. IV p. dex. 
(dist. end damaged); B473, ph. dist. d. III p. dex. (dist. end damaged); B480, ph. dist. d. IV p. dex.; B504, ph. dist. d. III p. sin. (prox. end damaged); B509, ph. 4 dist. d. IV p. sin. (dist. end damaged); B515, ph. dist. d. IV p. dex. (dist. end damaged); B533, ph. dist. d. IV p. sin. (damaged); B534, ph. II dist. d. III p. dex. ? sad. (damaged).

Pyrrhocorax cf. pyrrhocorax: EEH: B233, ph. dist. d. III p. dex. (dist. end damaged); B288, ph. dist. d. II p. dex. (dist. end damaged); B347, tmt sin. dist. (tr. mt. II damaged); B376, ph. dist. d. III p. sin. (dist. and prox. ends damaged); B423, ph. dist. d. I p. dex. (dist. and prox. ends damaged); B429, ph. dist. d. IV p. sin.; B436, ph. 3 d. III p. dex.; B437, ph. dist. d. III p. dex. (dist. end damaged); B443, ph. dist. d. IV p. dex. (dist. end damaged); B520, ph. dist. d. III p. sin. (dist. end damaged).

Pyrrhocorax sp. (P. graculus/pyrrhocorax): EEH: B267, ph. dist. d. III p. sin. (dist. end damaged); B289, ph. dist. d. II p. dex. (damaged); B348, ph. dist. d. III p. dex. dist. (prox. end damaged); B374, ph. dist. d. III p. dex. (dist. and prox. ends damaged); B48, ph. 3 d. IV p. dex.; cf. Pyrrhocorax sp.: EEH: B117, ph. dist. d. I p. dex.); B273, ph. dist. d. II p. sin. (dist. and prox. ends damaged); B332, vertebra cervicalis (splinter of prox. part); B390, vertebra cervicalis (splinter of caudal part).

Corvidae gen. indet. - 1: EEH: B3, ph. 1 d. I p. dex.

Corvidae gen. indet. - 2: EEH: B342, radius sin. prox.

cf. Corvidae gen. indet.: EEH: B541, ph. prox. d. majoris dex.

Sturnus sp. cf. S. vulgaris: EEH: B202, tbt dex. prox.; 456 cmc sin. dist.; cf. Sturnus sp. EEH: B424, ph. dist. d. III p. sin.; B454, ph. dist. d. III p. sin. (dist. end damaged).

Fringilla sp. cf. $\boldsymbol{F}$. coelebs: EEH: B187, hum. dex. prox.).

Carduelis sp. cf. C. carduelis: EEH: B194, cmc dex.

Carduelis sp. cf. $\boldsymbol{C}$. chloris: EEH: B444, mandibula prox. dex. (os articulare).

Carduelis sp.: EEH: B514, mandibula prox. dex. (os articulare);

cf. Carduelis sp.: EEH: B323, tmt dex. dist. ( $>C$. spinus).

Loxia curvirostra: LP: B188, tmt sin. dist.; EEH: B134, hum. dex. dist.; 135 hum. dex. dist.; B158, tmt dex. dist.; B207, tmt dex. dist.; B237, ulna dex. dist.; B240, ulna sin. dist.; B280, tmt dex. dist.; B292, tmt dex. dist. (epiphysis); B300, hum. dex. dist.; B334, ulna dex. dist.; B346, hum. sin.; $445 \mathrm{cmc}$ sin. dist.; cf Loxia curvirostra: EEH: B338, tmt sin. dist.; B341, femur sin. dist. damaged; B352, tmt sin. dist.; B406, ph. dist. d. II p. sin. (prox. end damaged); B408, tmt dex. dist. (tr. mt. III and IV damaged); B467, femur sin. dist.; B506, tmt dex. dist. (tr. mt. III and IV damaged).

Coccothraustes coccothraustes: LP: B159, hum. sin. (without epiphyses); EEH: B131, hum. dex. dist.; B203, tbt sin. dist.; B204, femur dex. dist.; B224, ulna dex. dist.; B262, ulna dex. dist.; B266, hum. dex. dist.; B281, ulna dex. dex.; B335, tmt sin. dist. (tr. mt. II damaged); B336, ulna sin. dist.; B377, cmc sin. prox.; B471, tmt dex. dist.; B496, tmt dex. dist. (epiphysis); B499, ulna sin; cf. Coccothraustes coccothraustes: EEH: B249, tmt dex. dist. (more robust); B378, ph. dist. d. I p. dex.; B401, ph. dist. d. I p. dex. (prox. end damaged); B403, ph. dist. d. III p. sin.; B407, ph. dist. d. IV p. dex.; 412 ph. dist. d. IV p. dex.; B503, tmt dex. dist. (tr. mt. II damaged); B519, tmt dex. dist.

Pyrrhula pyrrhula: LP: B209, mandibula sin. prox.; EEH: B243, cmc prox. dex.; B320, hum. sin. dist.; B375, os quadratum dex.; cf. Pyrrhula pyrrhula: LP: B175, mandibula sin. (pars articularis); EEH: B411, tmt sin. dist.; B337, tmt sin. dist.; B339, tmt dex. dist.

Emberiza calandra: EEH: B402, ph. dist. d. I p. dex. cf. Emberiza calandra: EEH: B191, tmt sin. dist. B493, ph. dist. d. IV p. sin.

cf. Plectrophenax nivalis: $\mathrm{EEH}$ : B257, tmt dex. dist. (tr. mt. II damaged); B307, tmt sin. dist.; B313, tmt dex. dist. (tr. mt. II damaged); B315, tmt sin. dist.; B398, tmt sin. dist. (tr. mt. IV damaged); B489, tmt sin. dist. (tr. mt. II damaged); B546, tmt dex. dist.

Emberiza sp. cf. E. cirlus: EEH: B367, hum. dex. dist.

Emberizidae gen. indet.: EEH: B173, tmt sin. dist.; cf. Emberizidae gen. indet.: EEH: B380, cmc sin. prox. (size of Plectrophenax nivalis).

Oscines Non-Corvidae indet.: EEH: B8, ph. 2 d. III p. sin.; B73, ph. 2 d. III p. sin.; B180, tmt dex. dist. (tr. mt. III and IV; \# Sturnus, Turdus, Monticola, Corvidae; tr. mt. III damaged); B322, tmt sin. dist. (tr. mt. III and IV); B325, tmt sin. dist. (epiphysis; tr. mt. II damaged); B326, tmt dex. dist. (tr. mt. III and IV; Non-Fringillidae); B330, tmt dex. dist. (tr. mt. II, III and IV; size of B. garrulus); B365, tmt sin. dist. (size of Bombicylla garrulus); B385, tmt sin. dist. juv. (Turdidae/ Sturnidae; epiphysis damaged); B494, tmt sin. dist. (tr. mt. II and IV damaged; size of C. cinclus); B512, tmt sin. dist. (tr. mt. II damaged); B521, tmt dex. dist. (tr. mt. III; NonFringillidae); B528, tmt dex. dist. (tr. mt. IV; Non-Fringillidae); B223, os quadratum dex.; B547, radius dex. dist.

Non-Passeriformes indet.: LP: B6, ph. 2 d. II p. dex.; B11, ph. 1 d. I p. sin.; B55, ph. dist. d. p. (dist. end damaged); EEH: B285, ph. dist. d. p. (dist. end damaged); B340, furcula symphysal part. 


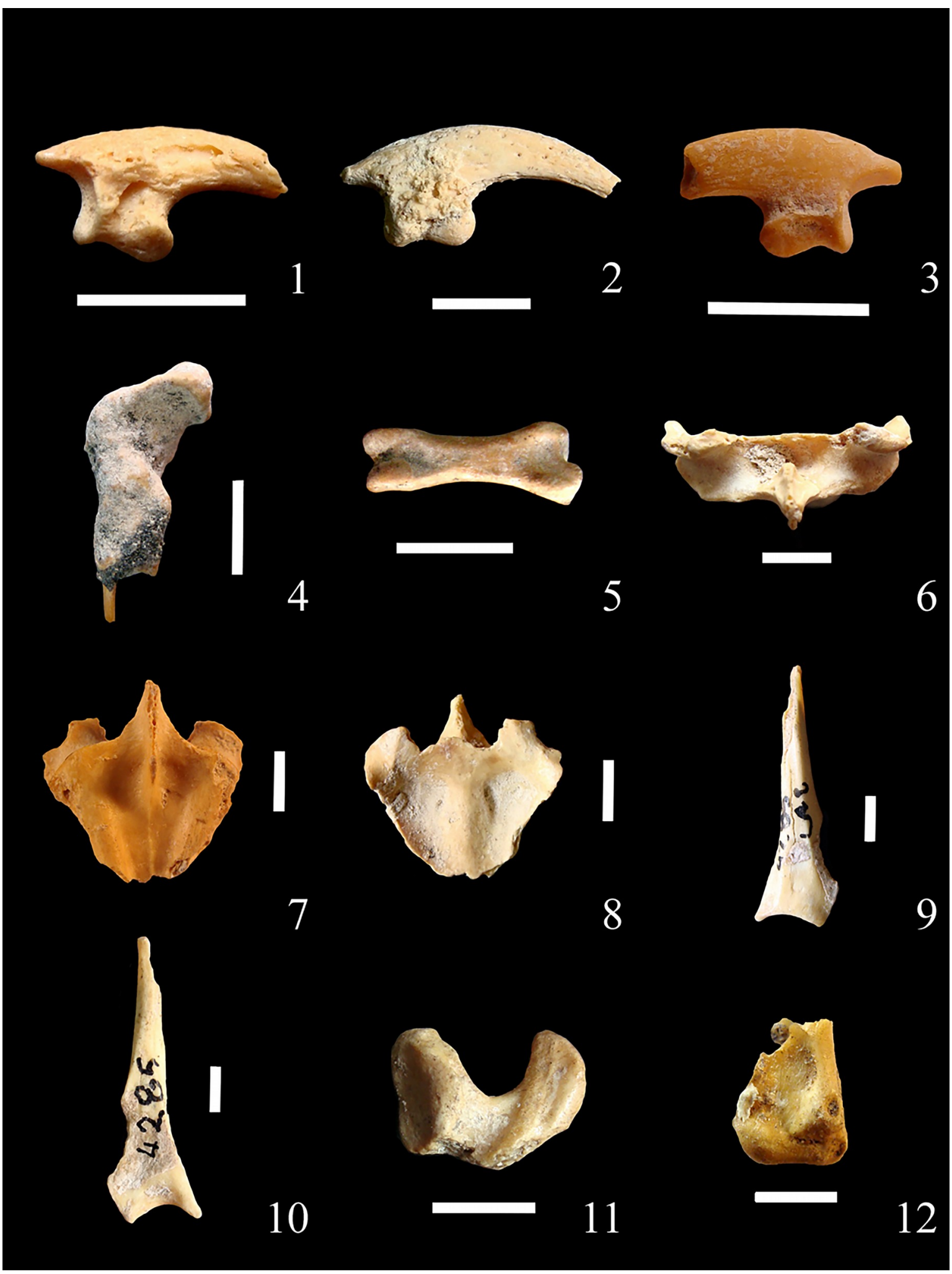

Plate 1. Avian finds from the Loutra Almopias Cave Fig. 1. Buteo sp. cf. B. lagopus, LAC B 63: distal phalanx of right digit IV, from a possible sub-adult individual. Fig. 2. Falco sp. cf. F. peregrinus: LAC B 93 distal phalanx of left digit IV. Fig. 3. Falco sp. cf. tinnunculus: LAC B 24 distal phalanx of right digit II. Fig. 4. Perdix perdix: LAC B 156 distal (humeral) part of left coracoid. Fig. 5. Alectoris graeca: LAC B 40 phalanx 1 of left digit I. Fig. 6. Francolinus francolinus: LAC B 163 sternum, pars coracoidalis - cranial view. Fig. 7. Francolinus francolinus: LAC B 163 sternum, pars coracoidalis - ventral view. Fig. 8. Francolinus francolinus: LAC B 163 sternum, pars coracoidalis - dorsal view. Fig. 9. Francolinus francolinus: LAC B 150 coracoid left prox. (sternal) - ventral view. Fig. 10. Francolinus francolinus: LAC B 150 coracoid left prox. (sternal) - dorsal view. Fig. 11. Tetrao tetrix: LAC B 139 ulnare left. Fig. 12. Lagopus cf. lagopus: LAC B 165 distal part of right humerus. Graphical scale: $5 \mathrm{~mm}$. 


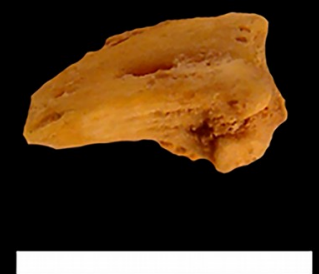

1
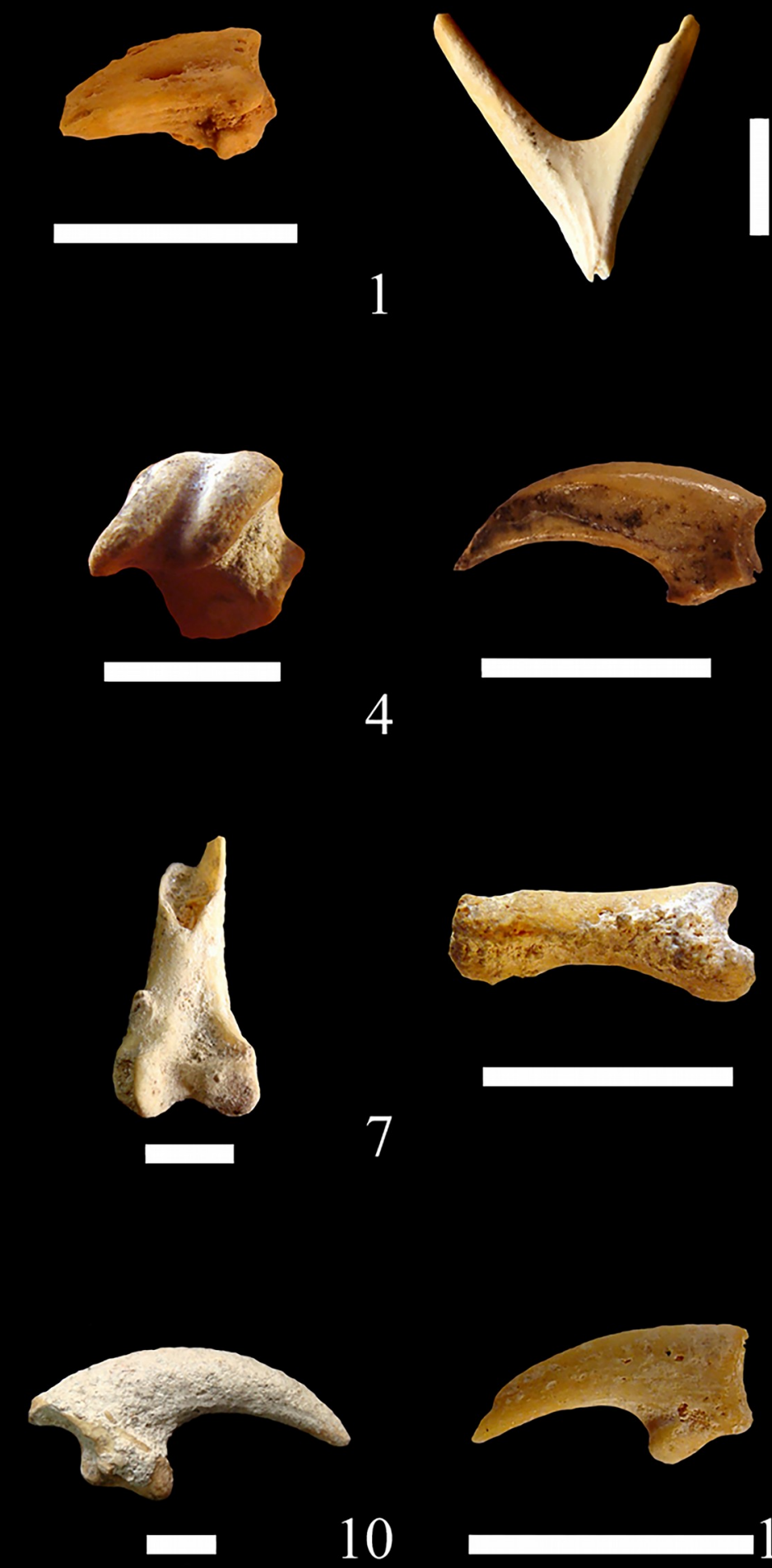

4

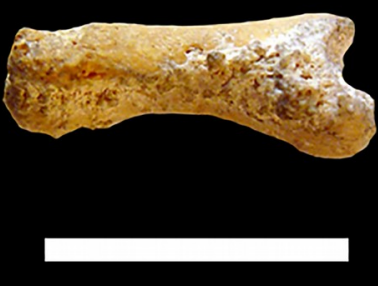

7
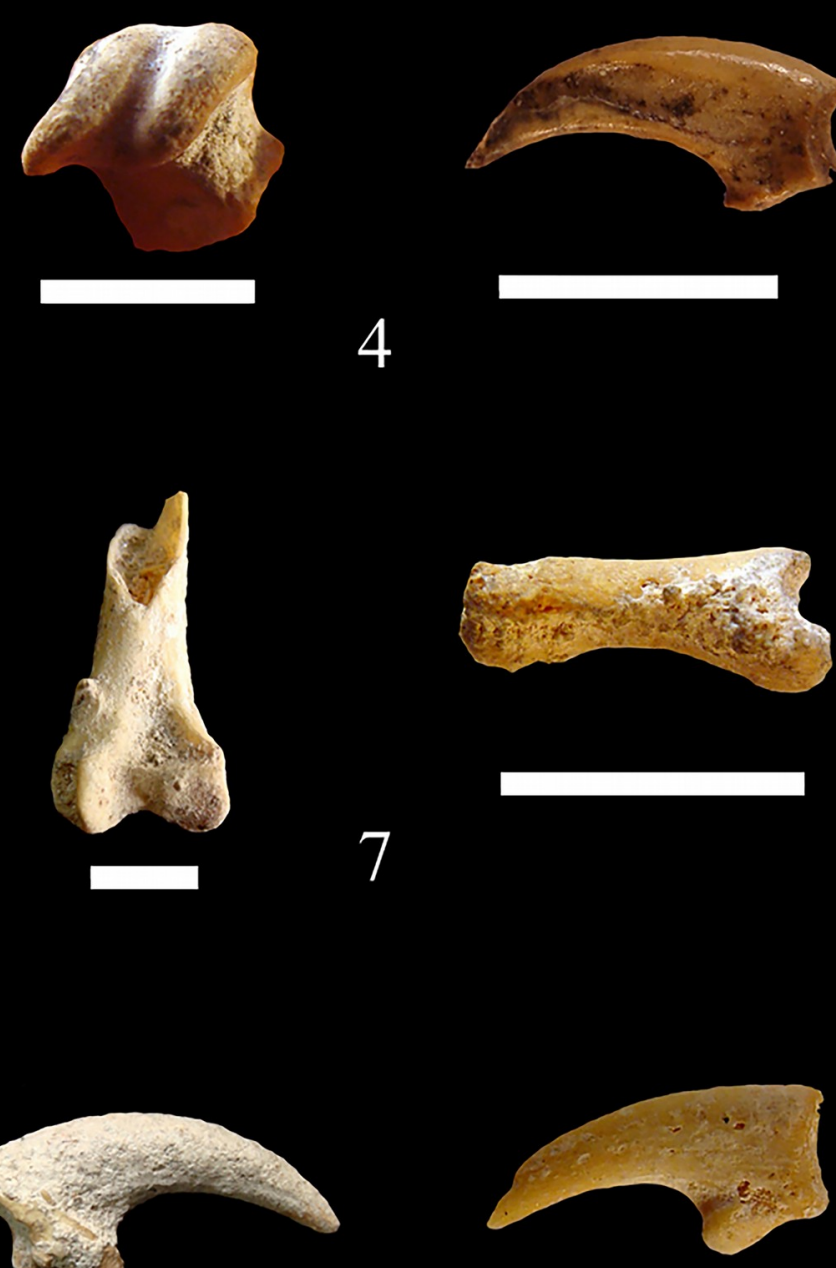

10

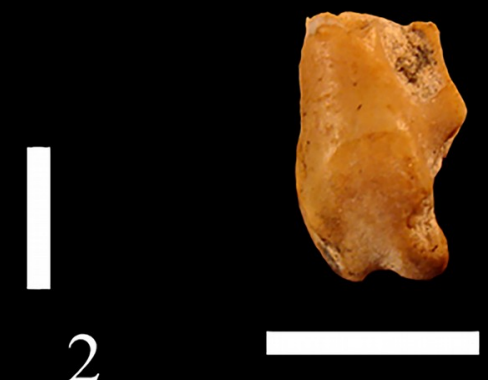

2

3

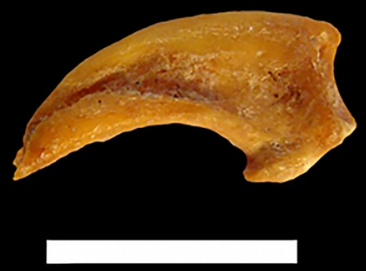

5

6

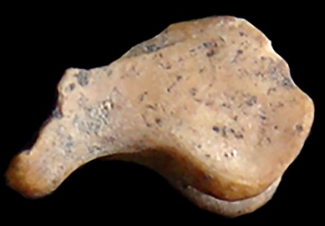

8

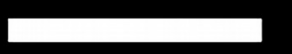

9

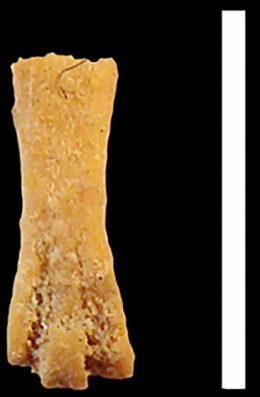

12

Plate 2. Avian finds from the Loutra Almopias Cave. Fig. 1. Lagopus cf. lagopus: LAC B 486 distal phalanx of right digit I. Fig. 2. Lagopus cf. lagopus: LAC B 166 furcula (symphysis clavicularis). Fig. 3. cf. Bonasa bonasia: LAC B 177 - distal part of right tmt (tr. mt. IV) - cranial view. Fig. 4. cf. Bonasa bonasia: LAC B 177 - distal part of right tmt (tr. mt. IV) - ventral view. Fig. 5. Columba cf. C. palumbus: LAC B 124 distal phalanx of left digit IV. Fig. 6. Columba cf. C. palumbus: LAC B 270 distal phalanx of right digit I. Fig. 7. Columba livia: LAC B 140 distal part of left femur. Fig. 8. Columba livia: LAC B 448 distal phalanx 3 of left digit IV. Fig. 9. Athene noctua: LAC B 38 distal phalanx 2 of right digit III. Fig. 10. Bubo bubo: LAC B 137 left distal phalanx of digit I. Fig. 11. cf. Otus scops: LAC B 481 left distal phalanx of digit IV. Fig. 12. Caprimulgus sp.: LAC B 331 distal part of right tarsometatarsus of a juvenile individual. Graphical scale: $5 \mathrm{~mm}$. 


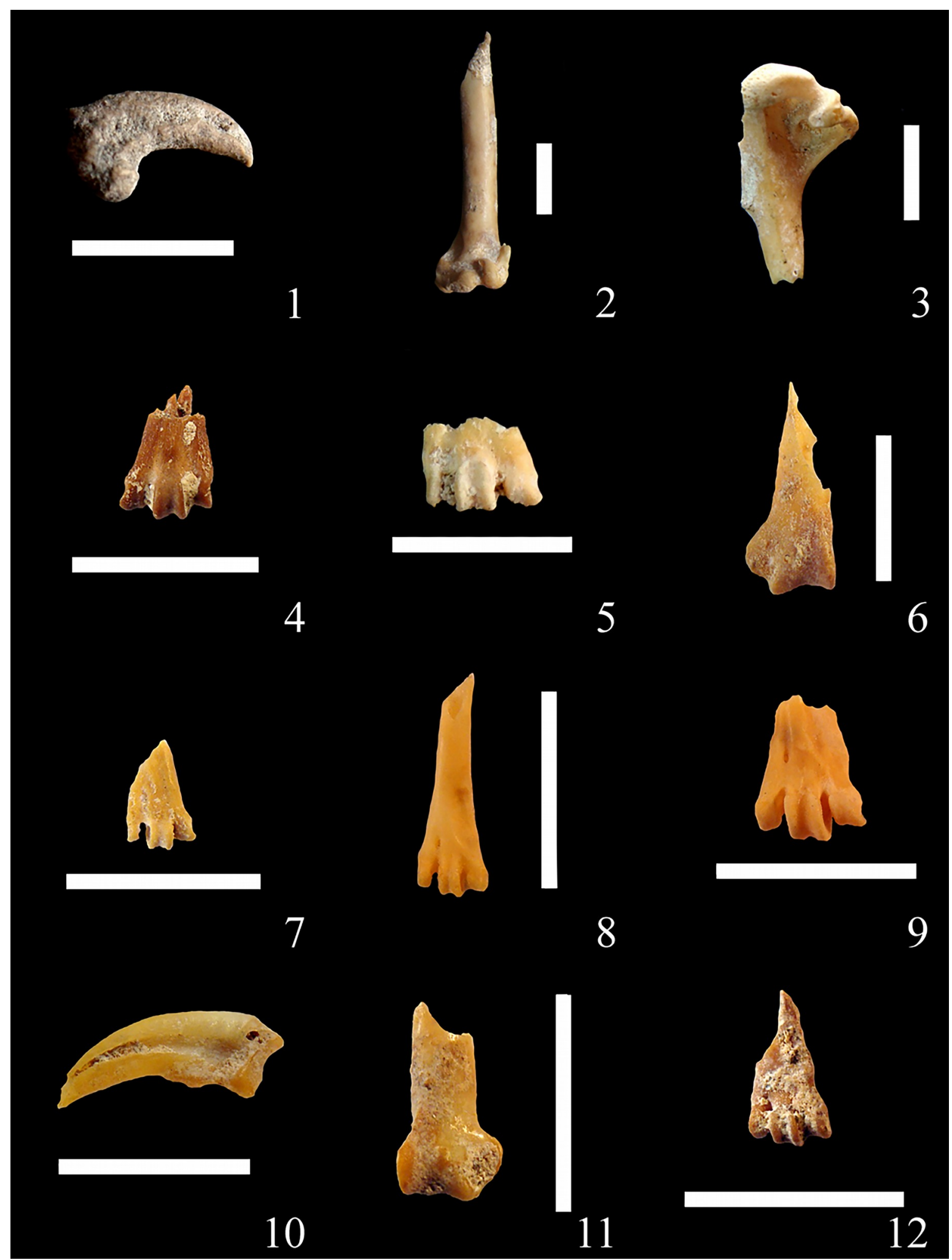

Plate 3. Avian finds from the Loutra Almopias Cave. Fig. 1. cf. Dryocopus martius: LAC B 123 left distal phalanx of digit IV. Fig. 2. Alauda sp.: LAC B 132 distal part of left humerus. Fig. 3. Galerida sp. cf. G. cristata: LAC B 213 proximal part of left humerus. Fig. 4. Lulula arborea: LAC B 258 distal part of left tarsometatarsus. Fig. 5. Melanocorhypha calandra: LAC B 186 distal part of right tarsometatarsus. Fig. 6. cf. Hirundo sp.: LAC B 478 distal part of right ulna. Fig. 7. Riparia/ Ptyonoprogne: LAC B 333 distal part of left tarsometatarsus. Fig. 8. Anthus sp.: LAC B 492 distal part of left tarsometatarsus. Fig. 9. Bombycilla garrulus: LAC B 544 distal part of left tarsometatarsus. Fig. 10. Cinclus cinclus: LAC B 239 distal phalanx of right digit III. Fig. 11. Phoenicurus sp. cf. P. ochruros: LAC B 309 distal part of left ulna. Fig. 12. Erithacus/Luscinia: LAC B 327 distal part of left tarsometatarsus. Graphical scale: $5 \mathrm{~mm}$. 

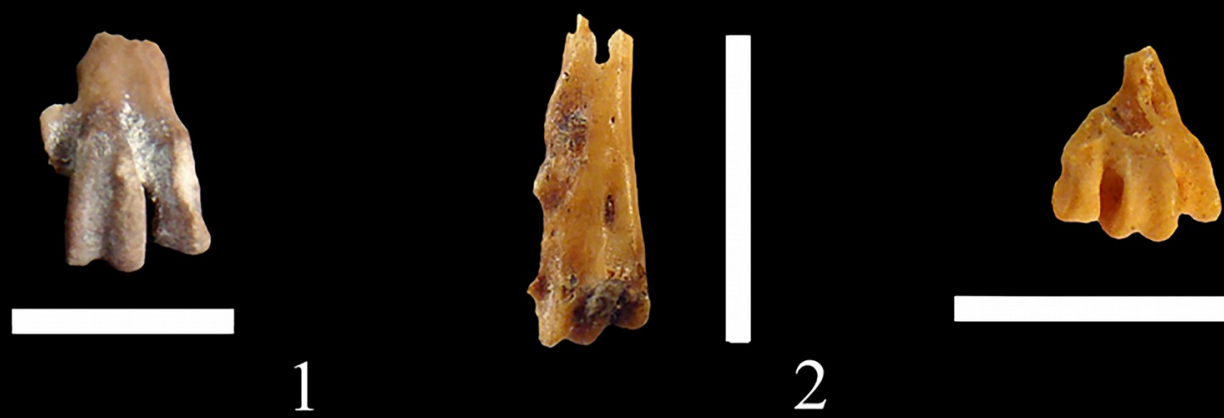

1

2

3
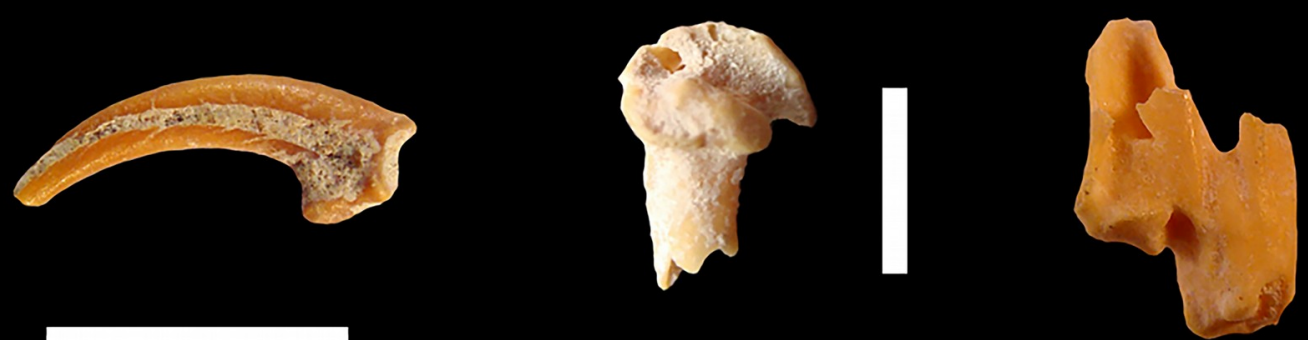

5
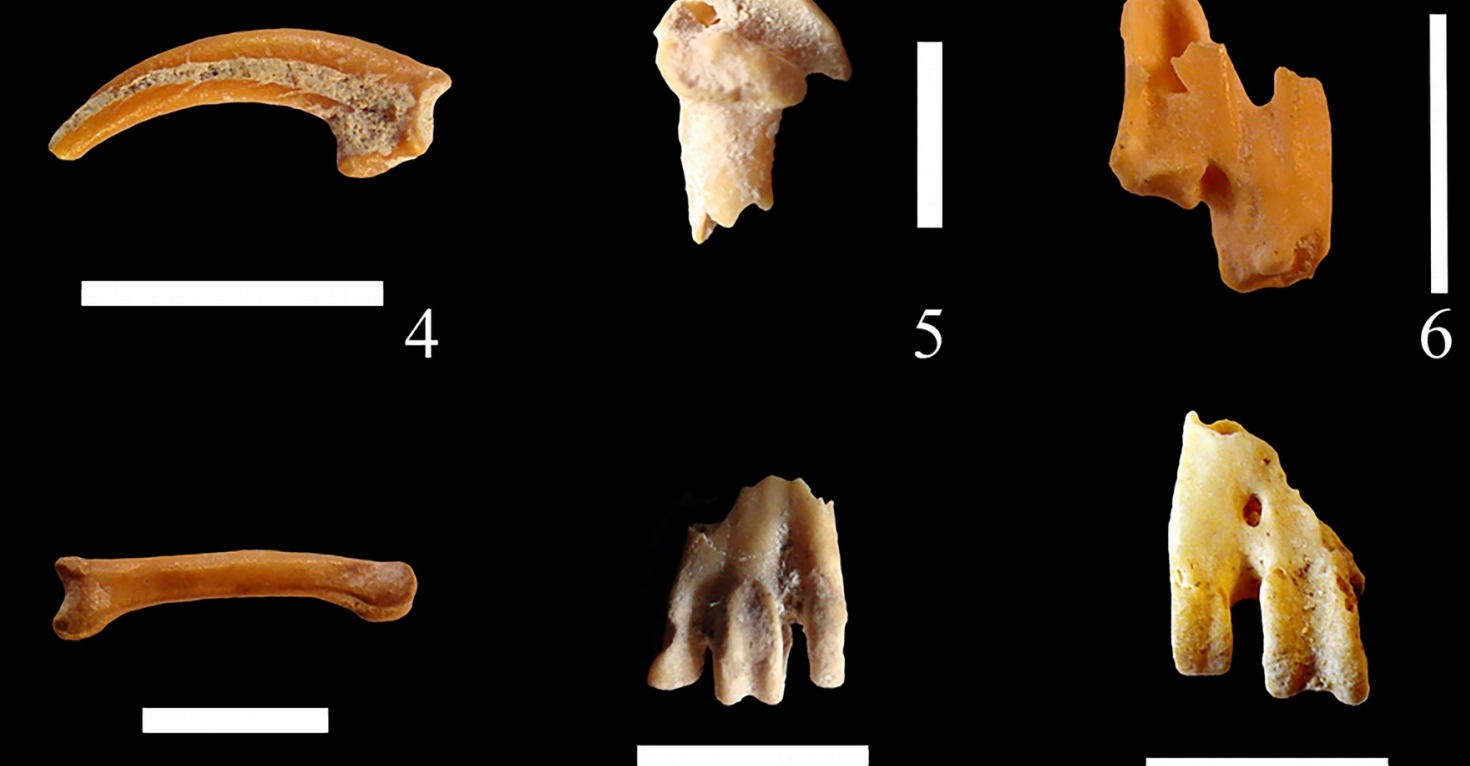

6

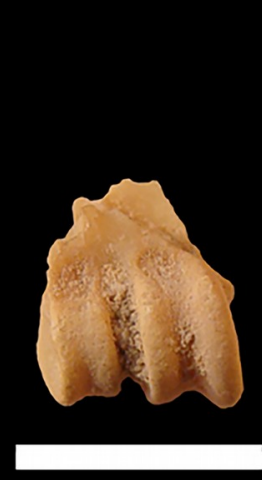

7
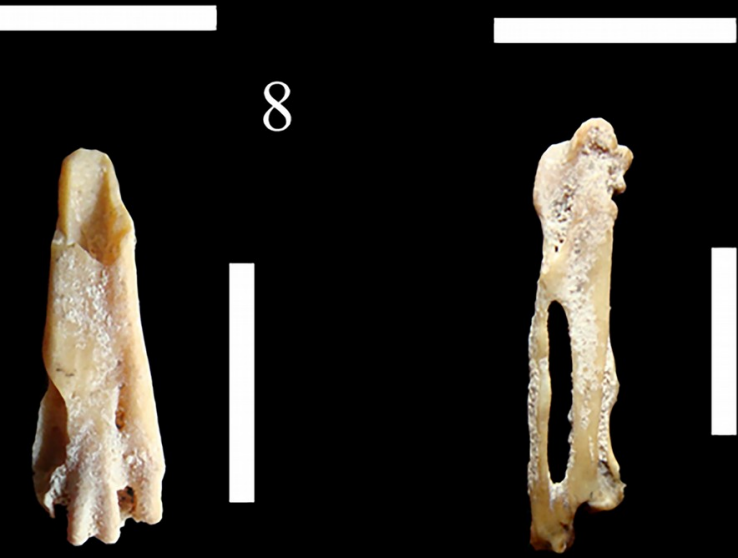

9
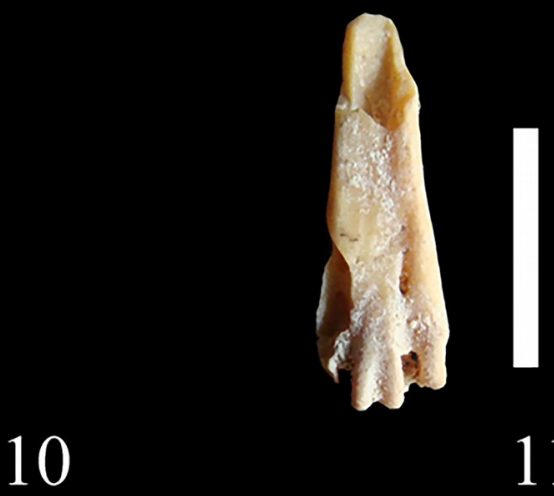

11

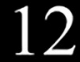

Plate 4. Avian finds from the Loutra Almopias Cave. Fig. 1. Turdus sp. cf. T. viscivorus: LAC B 190 distal part of right tarsometatarsus. Fig. 2. Sylvia sp. cf. S. borin: LAC B 329 distal part of right tarsometatarsus. Fig. 3. Parus major: LAC B 321 distal part of right tarsometatarsus. Fig. 4. Sitta cf. europaea: LAC B 355 left distal phalanx of digit III. Fig. 5. Sturnus sp. cf. S. vulgaris: LAC B 202 proximal part of right tibiotarsus. Fig. 6. Sturnus sp. cf. S. vulgaris: LAC B 456 distal part of left carpometacarpus. Fig. 7. Garrulus glandarius: LAC B 61 phalanx 3 of right digit III. Fig. 8. Pica pica: LAC B 195 distal part of left tarsometatarsus. Fig. 9. Pyrrhocorax cf. pyrrhocorax: LAC B 347 distal part of left tarsometatarsus. Fig. 10. Pyrrhocorax graculus: LAC B 20 distal part of right tarsometatarsus. (tr. mt. II and III). Fig. 11. Emberiza calandra: LAC B 191 distal part of left tarsometatarsus. Fig. 12. Carduelis sp. cf. C. carduelis: LAC B 194 right carpometacarpus. Graphical scale: 5 $\mathrm{mm}$. 


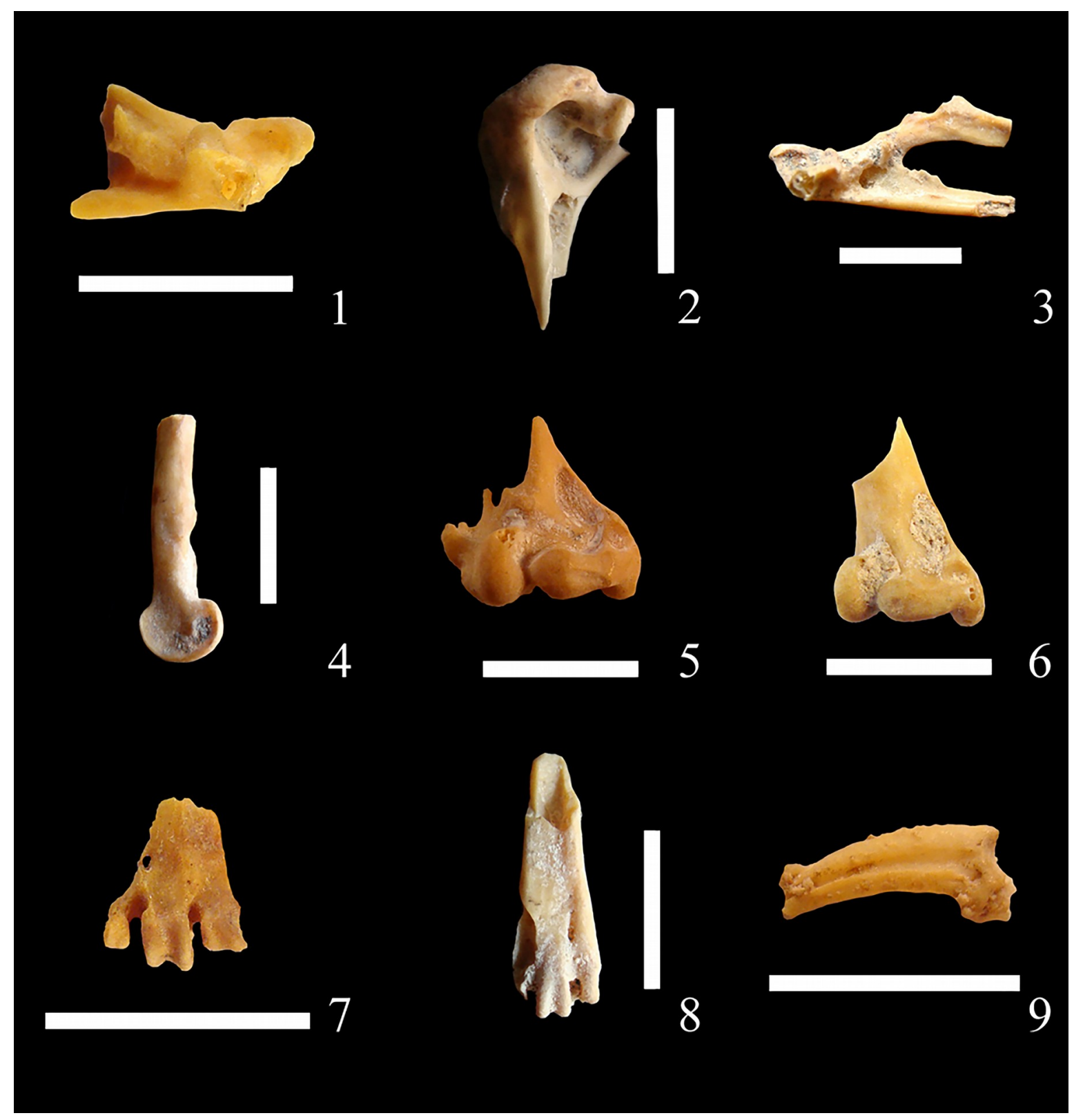

Plate 5. Avian finds from the Loutra Almopias Cave. Fig. 1. Chloris sp. cf. C. chloris: LAC B 444 proximal part of right mandibula (os articulare). Fig. 2. Fringilla sp. cf. F. coelebs: LAC B 187 proximal part of left humerus. Fig. 3. Pyrrhula pyrrhula: LAC B 209 proximal part of left mandibula. Fig. 4. Coccothraustes coccothraustes: LAC B 203 distal part of left tibiotarsus. Fig. 5. Loxia curvirostra: LAC B 134 distal part of right humerus. Fig. 6. Emberiza sp. cf. E. cirlus: LAC B 367 distal part of right humerus. Fig. 7. cf. Plectrophenax nivalis: LAC B 307 distal part of left tarsometatarsus. Fig. 8. Emberiza calandra: LAC B 191 distal part of left tarsometatarsus. Fig. 9. cf. Emberiza calandra: LAC B 402 phalanx of right digit I. Graphical scale: $5 \mathrm{~mm}$. 